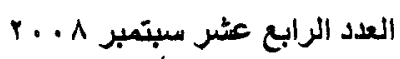 الجزء الأول عبئبر

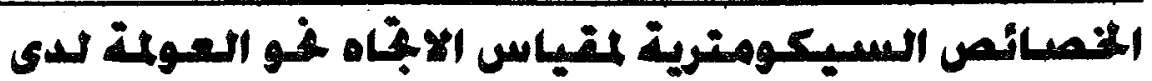

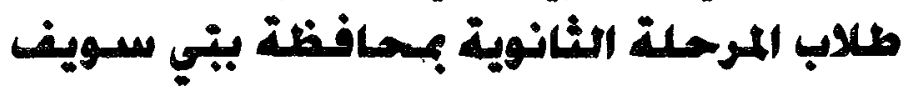 \\ s) ?}

محمد حسين سعيل حسين

ملرس علم النفس التعليمي

كلية التربية-جامعة بذىسويف النفي التعيع

11لملنص:

هدفت الدراسة الحالية إلى التحقق من الخصائص الـسيكومترية لمقيـاس

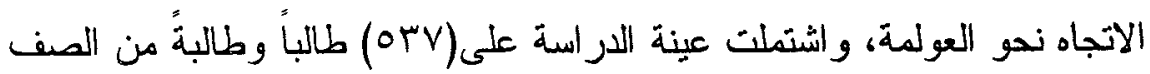

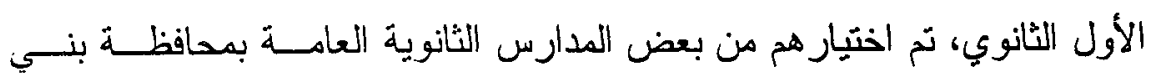

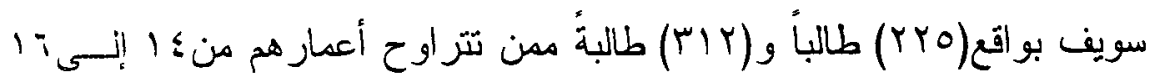

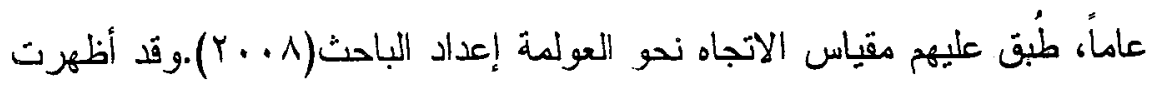

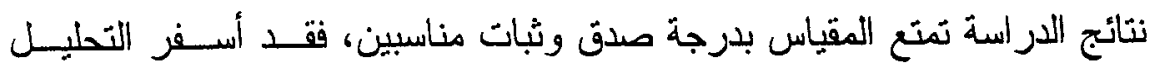
العاملي الاستكشافي للمقياس بطريقة المكونات الأساسية وتدوير المحاور بطريقة

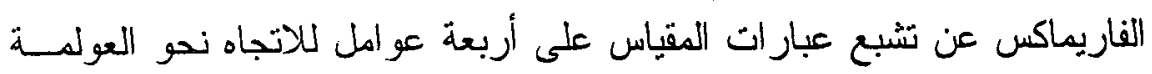

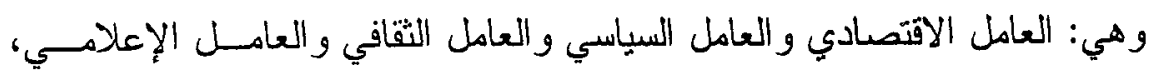

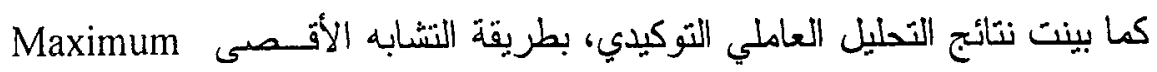

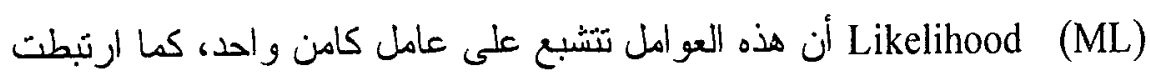
درجات الطلاب على المقياس بدرجاتهم على مقياس رثب الهوية إعــداد محمــد

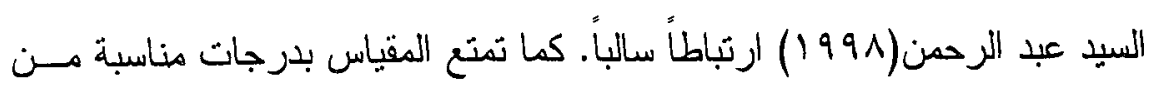

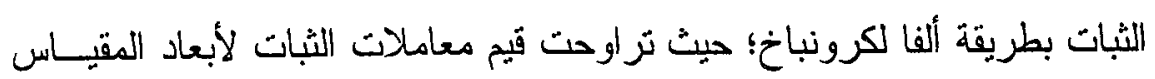

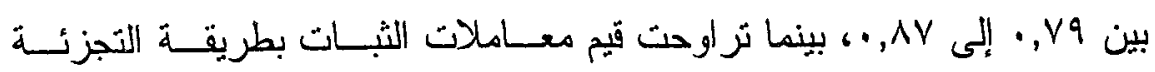

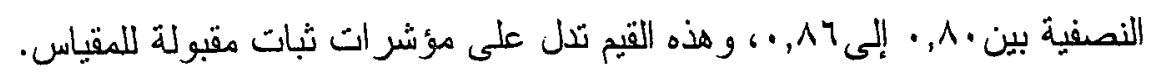


يُعد الاتجاه من المفاهيم النفسية والاجتماعية الهامة، كما أنه مــدخل

ضروري إلى فهم كثير من المفاهيم الأخرى التي تـــرتبط بـسـلوك الأفــر اد و علاقانهم، ولهذا يعتبر حجر الزاوية في بناء علم النفس الاجتماعي، حيـث بعتبره من المفاهيم المركبة التي تحتوي على قدر كبير من التعميم و التجريد.

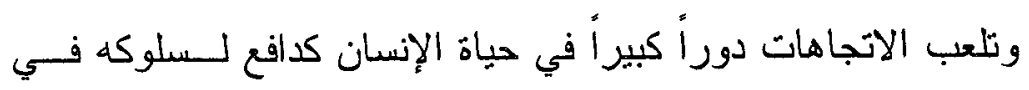

أوجه حياته المختلفة لذلك فقد احتل موضو ع الاتجاهات مكانة متميزة في علم النفس بشكل عام، وفي مجال علم النفس الاجتماعي بشكل خاص، وذلك لأن الاتجاهات النفسية الاجتماعية تعتبر من أهم نواتج عملية التنشئة الاجنماعية. فالاتجاه له أهمية كبيرة في توجيه سلوك الفرد مدا دفع كثير من الباحثين إلى اعتبار موضوع الاتجاهات هو المحور الأساسي في علم الــنفس باعتبــاره وثيق الصلة بسلوك الفرد في المو اقف المختلفة، (فؤاد البهـيكي، ســـد عبــد

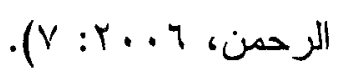

ويتكون الاتجاه النفسي عند الفرد ويتطور من خلال التفاعل المبادل

بين الفرد وبين بيئته، ونكوين الاتجاه النفسي بغض النظر عن كونه سالباً أو

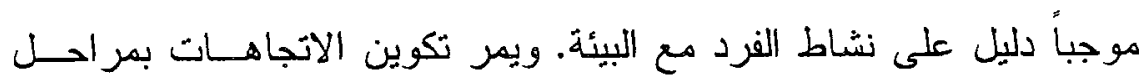
متعددة أول هذه المراحل هي المرحلة الاختيارية أو الإدر اكية المعرفية وتبدأ

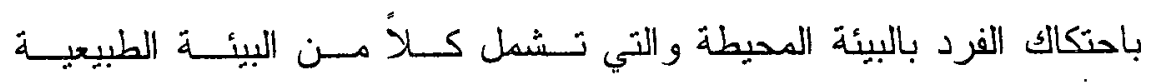
والاجنماعية، حيث ترثبط هذه المرحلة بنشاط الفرد الــدائب فــي المو اقـف الاجتماعية التي يمر بها في البيئة التي بعيش فيها حيث يفحص ويختبر كـل تفاعلاته الشخصية مع غيره و علاقاته الاجنماعية مع المحبطين به، ويراجع كل الأحداث التي يشارك فبها في محاولة لإدر اك عناصر بيئنه مما بجعلــها 


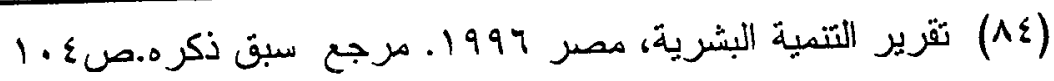

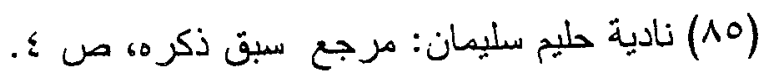

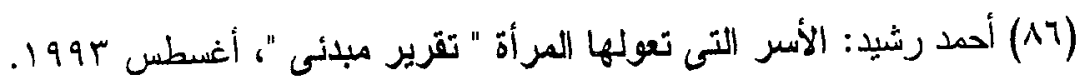
(AV)

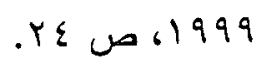

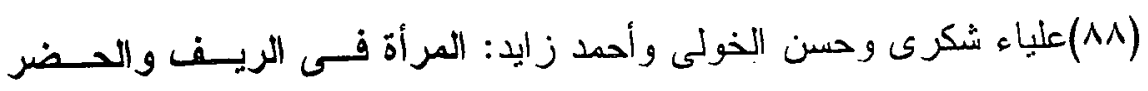

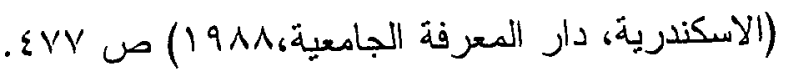

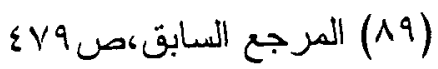

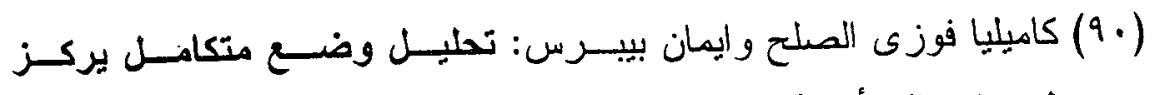

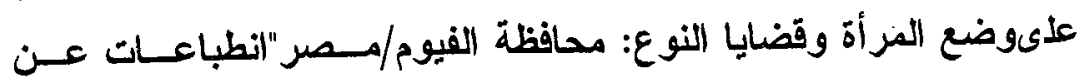

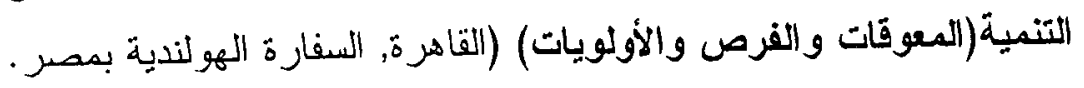

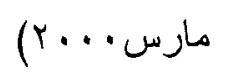

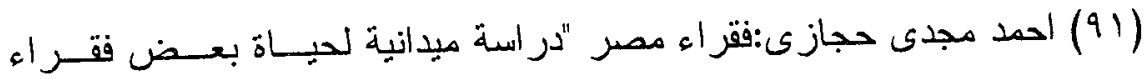

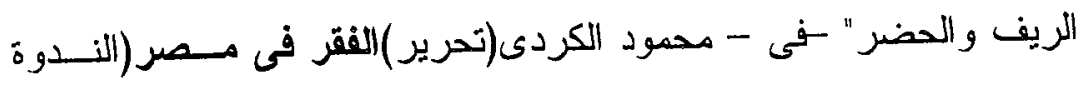

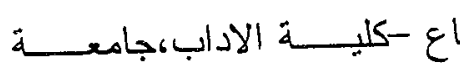

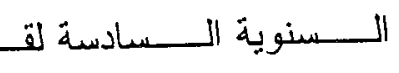

$$
\begin{aligned}
& \text { القاهرة }
\end{aligned}
$$

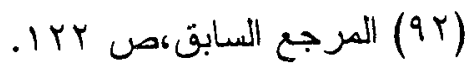

(ب9)أنظر فى ذلك: نجوى عبد الحميد محمد: أطلس الصناعات البيئية "بحـــ

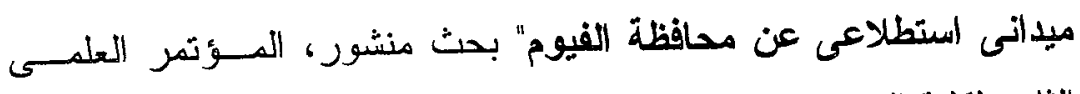

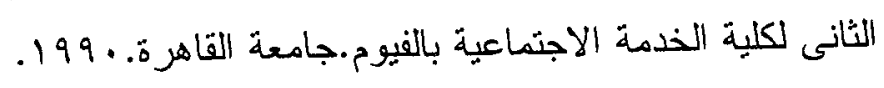

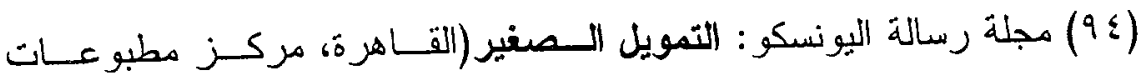

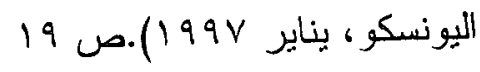


,

$-$ 


$$
\text { العدد الرابع عشر سبتمبر ^ م. الجزء الأول }
$$

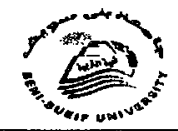

جامعة بني سويف (مجلة كليةٌ التربيةة

(01)محمد سعد أبو عامود:الوظائف الجديدة للدولة فى عصر العولمة - مجلة

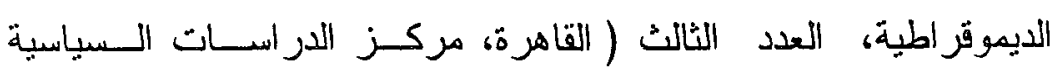

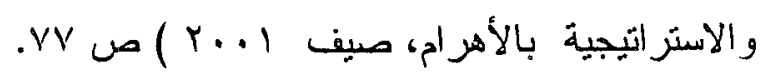

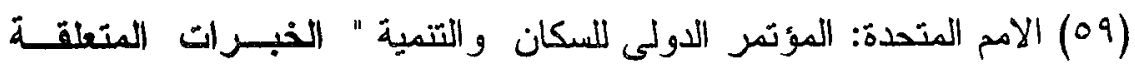

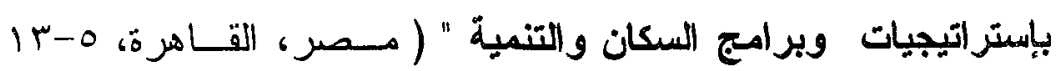

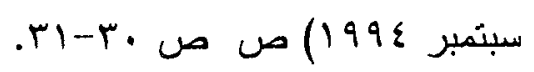

(60)Lindal Swonson: Household structure and Resources in Femole Headed Family Households (San Francisco, the Annual Meeting of the Population Association of American, 1999 ).

(61)Jill Findeis and Leif Jemen:Poverty Labor Markets, and the Potential Among Single Female Heoded Fomilies in Rurol South (the Pensylvania state univeristy , Population Research Institute, 2001)

(62) Scarch in Internet about:- Female Headed Households in 15-6-2007

(63) Nahed Motie: Female Headed Households in Iran:Civil Socicty, VOL.9, Issue.99.(cairo,Ibn Khaldun Centre for Development Studies, March,2000) (64) ) Search in Internet about: Women in Poverty:Bulgaria Povrty in Households Heoded Women. in 1-7-2007 (70) تقرير مقام من الجمعيات الاهلية المصربية للمنتدى العـالمى للمـر أة " بكـين

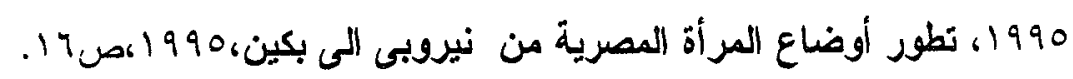

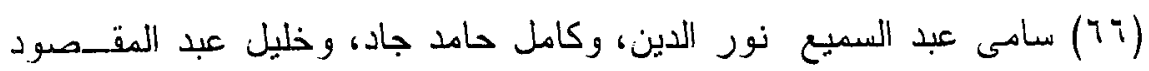

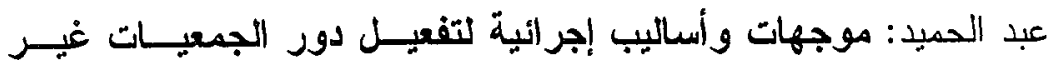

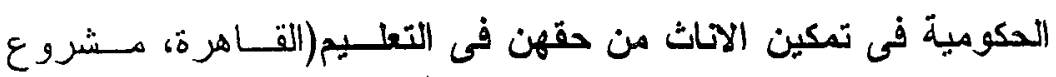

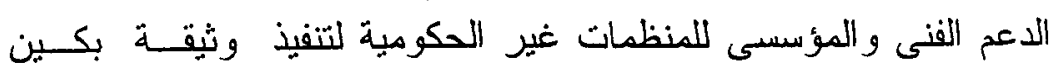
.97 ص)(1999 
(TV) نادية حليم سليمان: الفقر والنساء المعيلات لأسر" الابعاد وسبل المواجهة

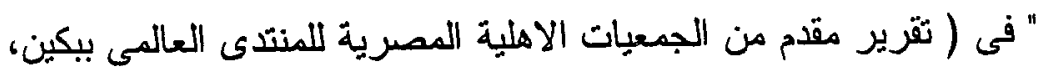

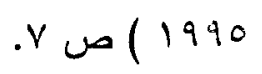

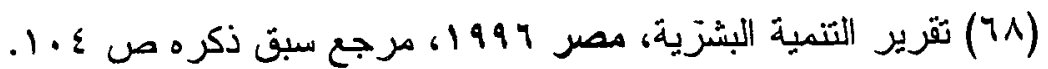

(69) UNDP: Human Development Report 1994. P.4

(70) UNDP: Human Development Report.2000. P.17

(71) Ibid.P.17.

(72) Ibid.P. 17.

(73) Ibid.P.733.

(74) Ibid:P.78.

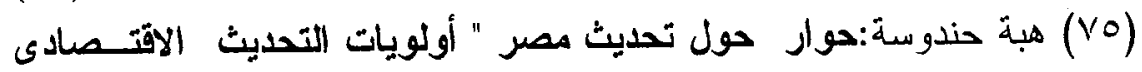

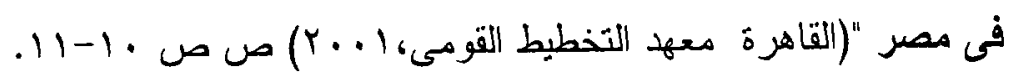

$\left({ }^{76}\right)$ UNDP: Human Development Report , 2001.

$\left({ }^{77}\right)$ UNDP: Human Development Report, 2000.

(78) Population Reference Bureou: Women of our World Data Sheet ,(Washington D.C, 2001)

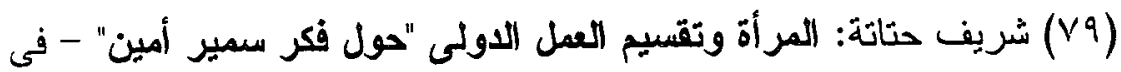

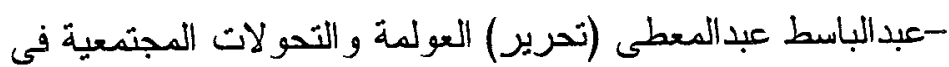

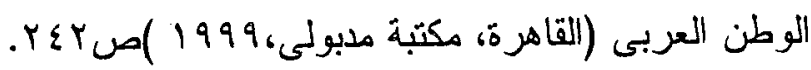

- هبة أحمد عبد اللطيف: دور المنظمات غير الحكومية في تمكين المرأة

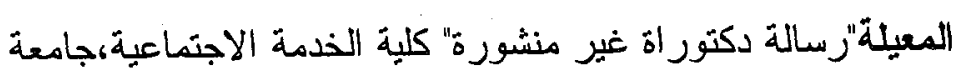

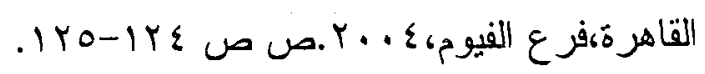

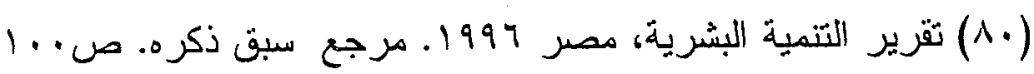

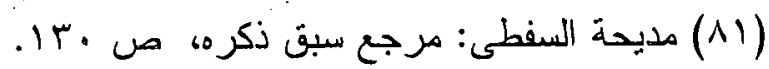

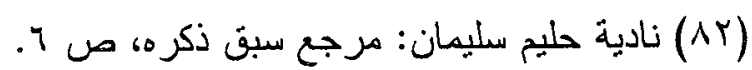

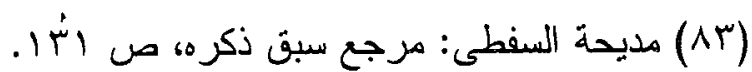




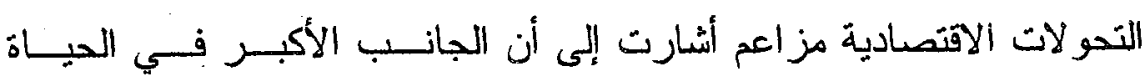
الاجتماعية سوف يتحدد من خلال عمليات "عولمة" تذوب فيها الخصوصيات الثقافية وتسودها حضارة عالمبة، هي الحضارة الغربية، (أحمد المهدي عبد

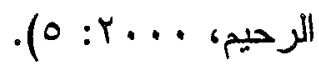

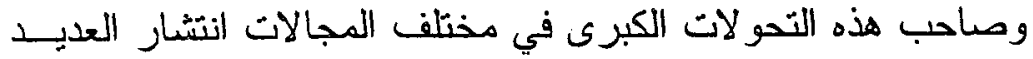

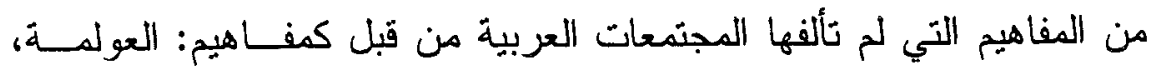

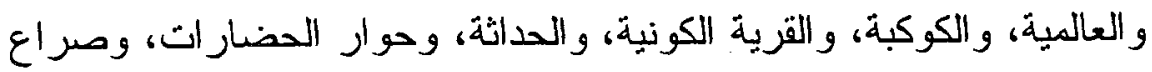

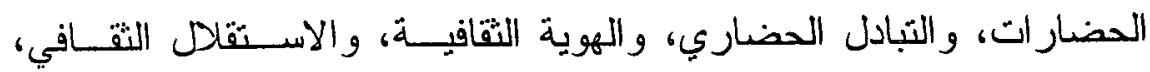

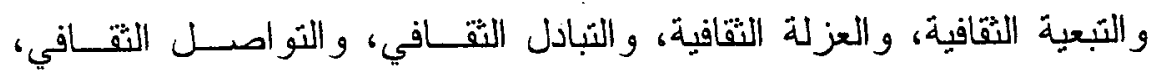

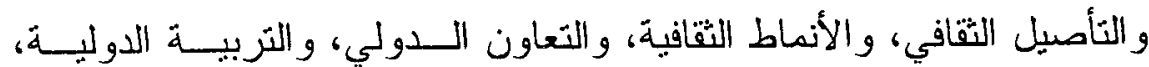

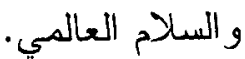

وقد بدأ فكر العولمة في ظل هذا يفرض نفسه على الساحة العالميـــة

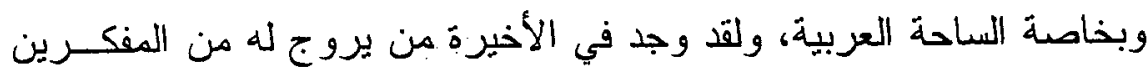

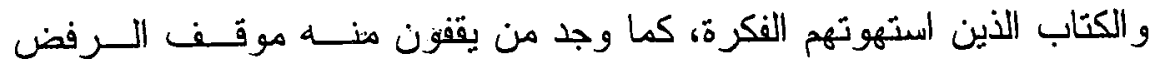

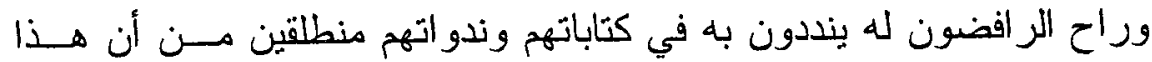

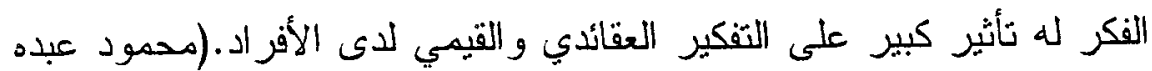

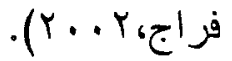

ويعتبر مفهوم العولمة من المفاهيم التي لاقت اهنمــام العديـــــــن فئن

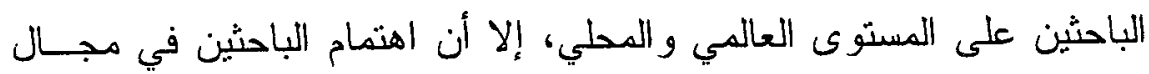

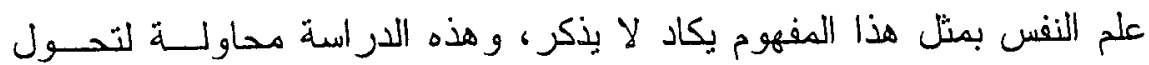
الباحثين في مجال علم النفس بدر اسة هذه الظاهرة در اسة علمية موضـــو عية

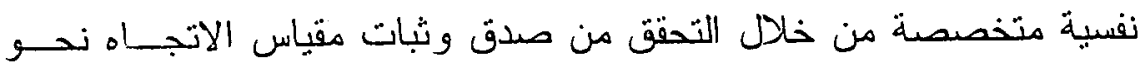
العولمة لدى عينة من طلاب المرحلة الثانوية بمحافظة بني سويف. 
مشاشكالة الدرالمانة:

تأخذ العولمة أشكالاً متعددة منهـــا العولمـــة الاقتــصادية، و العولمـــة

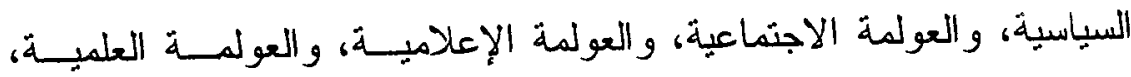

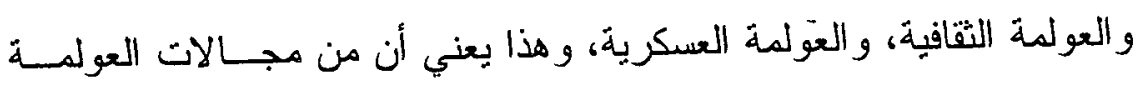
الافتصاد، و السياسة، و التربية، و الاجنماع، و الإعلام، و التقافة، و العسكرية.

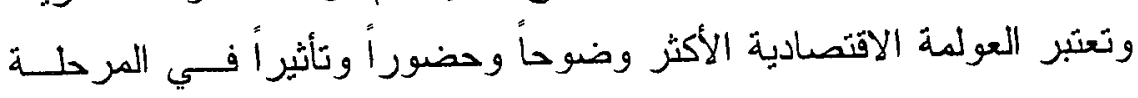
الر اهنة، وهي تبير إلى تحرير الاقتصاديات القومية ونزكها لقوى الــسوق

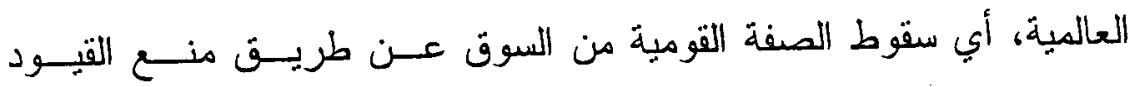

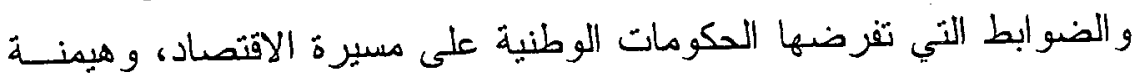

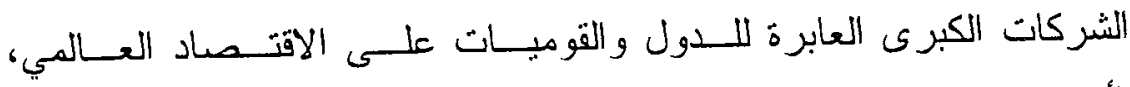

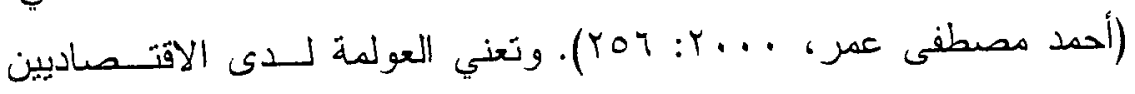
العملية التي يتم فيها تنظيم و إجراء النشاط الافتصادي بكافة أنو اعــهـ قوميــان وإقليمياً ودولياً، بدون وجود حدود ومحددات فاصلة، ومن ثم يسرتبط هــان

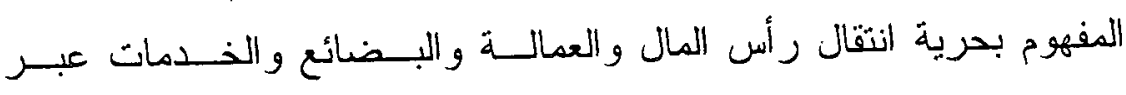
القوميات، (Andrews, 1994). وفي العولمة السياسية لا تكون الدولة هي الفاعـلـ الوحيـد علـى المسرح السياسي العالمي، ولكن ثوجد إلى جانبها هيئات متعددة الجنـسيات ومنظمات عالمية، وجماعات دولية وغير ها من التظظيمات الفعالة التي تسعى إلى تحقيق مزيد من الترابط والتاخل والتعاون و الاندماج الــدولي، بحبــث تكف الدول عن مبدأ السيادة الذي بأخذ في التقلص نحت تأثير حاجة الــدول إلى التعاون فيما بينها في المجالات الافتصادية و البيئية و التكنولوجية وغيـر ذلك (محمد شومان، 9999 1: 17 1). أي أن المفهوم السياسي للعولمة يـسشير إلى عملية يتم من خلالها إيجاد أدوات جديــدة للحكــم و الإدارة ذات طــبـع 
يكتسب خبرة بكل محتوياتها تكون بمثابة تراث معرفي، (زايسـد الحسارثي، (rr: :199r

و المرحلة الثانية هي المرحلة التفضيلية أو التقييمية و التــي تثميـز

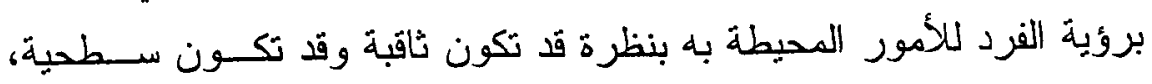

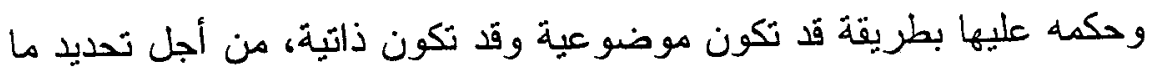

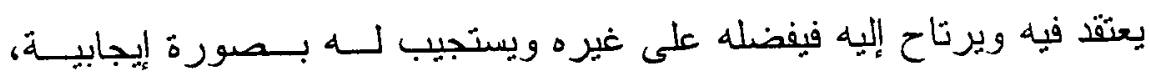

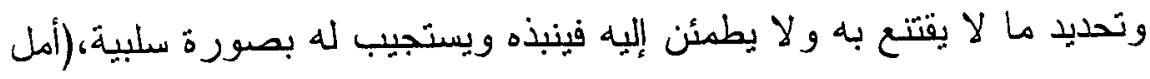

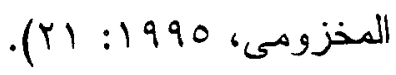
أما المرحلة الثالثة فهي المرحلة الاستقرارية أو الثقريريسـة والتـي التهي

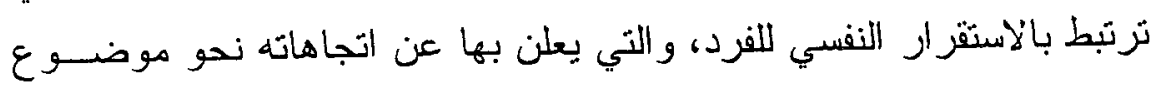

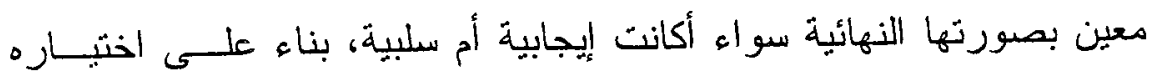

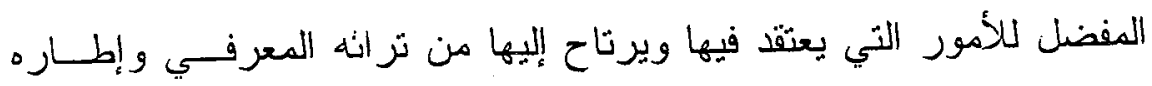

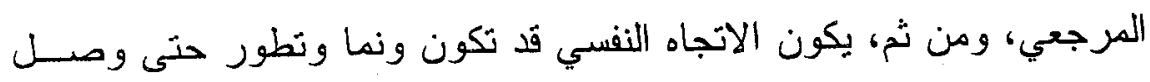

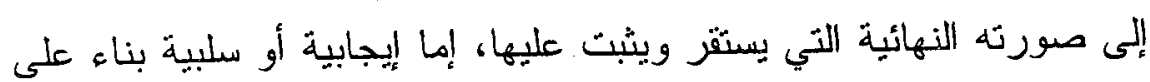

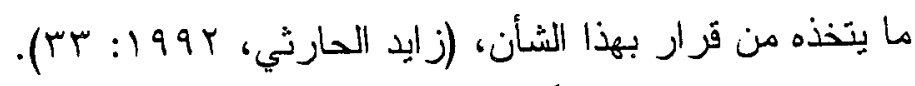

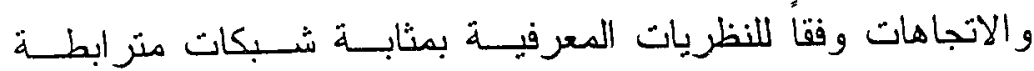

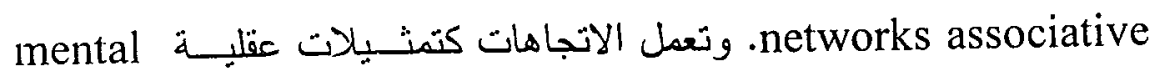
representations داخل العقل، وتنكون هذه التمثيلات من وحدات معرفية

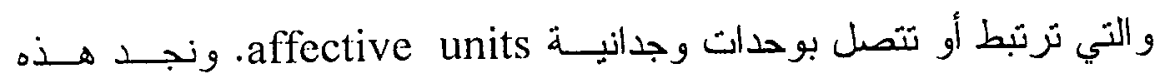
الروابط أو الوصلات links داخل الاتجاه، وكذلك بين الاتجاهات المختلفة.

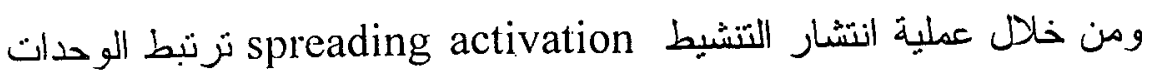
القديمة (المعرفية والانفعالية) بعناصر جديدة، مما يسبب ظهور اتجاه جديسـ نحو موضوع ما، نتيجة ارنباطه باتجاه قديم،(Tesser \& Shaffer, 1990). 
وتتخذ الاتجاهات مما بحيط بالفرد من أشخاص أو طبقات اجتماعية

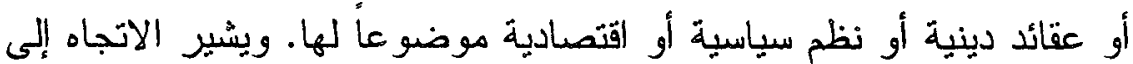
ميل مؤيد أو مناهض أو محايد لهذا الموضوع، وقد يتحرك الاتجــاه فــوق

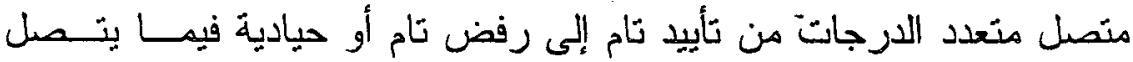
بموضوع الاتجاه، وقد تتضاعل اتجاهات الأفراد وثتمركز حول عالمه الضيق فقط حيث أسرته ومشاكله و التوحد مع اتجاهاتها و الدفاع عن هذه الاتجاهات بعنف وغضب و عدوان، وقد تتسحب هذه الاتجاهات على مدرسته أو الحسي ومي وني

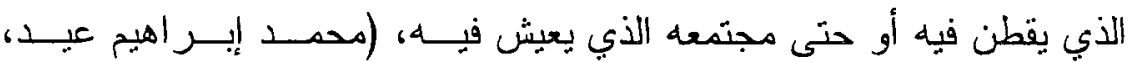
.(7)-OV:1991

ويمكن القول أن كل ما يقع في مجال الفرد على المـستوى النفسسي والاجتماعي يمكن أن بكون موضع اتجاه من اتجاهاته النفسية أو الاجتماعية

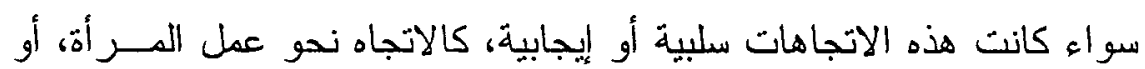

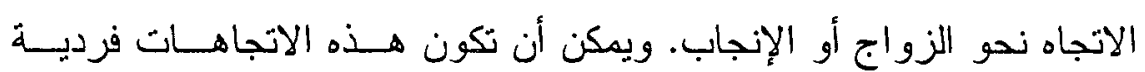

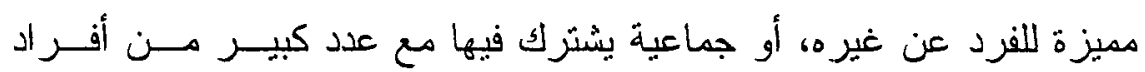

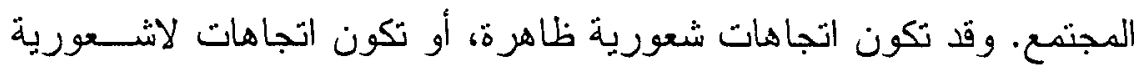

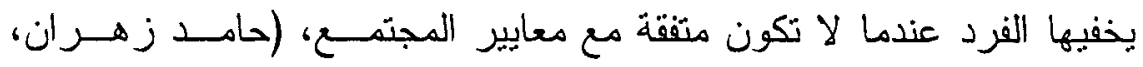
.(1) . : :...

ولقد برز في بو اكير العقد الأخير من القرن العشرين نظام عـالمي

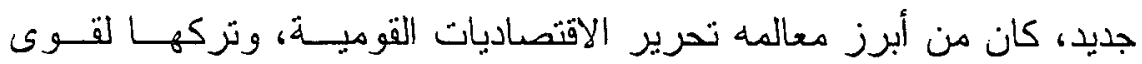

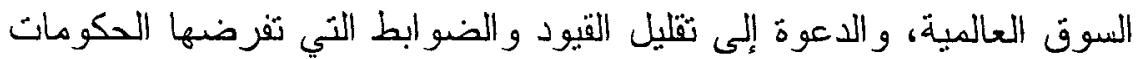

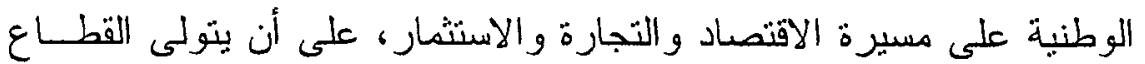

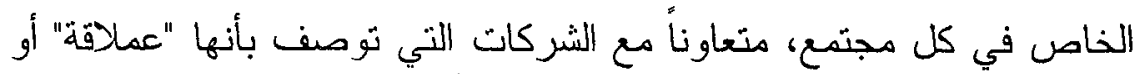

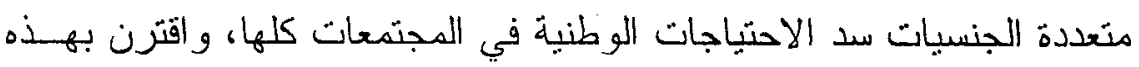


عالمي، كرد فعل للتحول العولمي الاقتصادي-أي إحداث تغيرات شاملة في النظام العالمي السياسي و الاقتصادي، (Andrews, 1994).

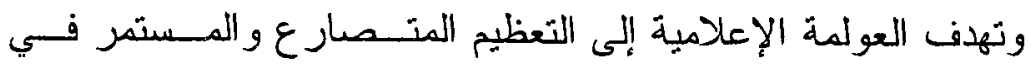
قدرات وسائل الإعلام و المعلومات على تجاوز الحدود السياسية والثقافية بين المجتمعات، بفضل ما توفره التكنولوجيا الحديثة و التكامل و الانـــدماج ببــين وسائل الإعلام و الاتصال و المعلومات، وذلك لدعم عملية نوحبد ودمج أسوات العالم من ناحية وتحقيق مكاسب لشركات الإعلام و الاتصالات و المعلومسـات ولهات

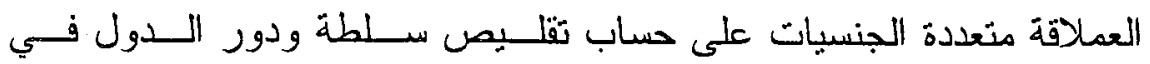
المجالين الإعلامي و الثقافي من ناحية أخرى. أما العولمة الثقافية فهي تعنــي ولئي انتقال تركيز اهنمام ووعي الإنسان من المجال المحلي إلى المجال العالمي،

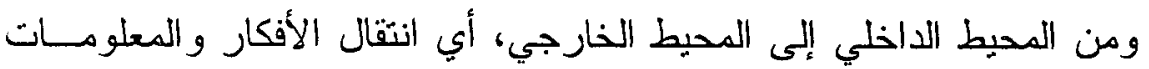
و البيانات والاتجاهات و القيم والأذواق على الصعيد العالمي، وبأقل قدر مــن القيود و العر اقيل و الضوابط، ففي ظلل العولمة الثقافية يزداد الوعي بعالميــة

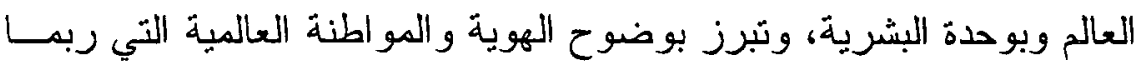

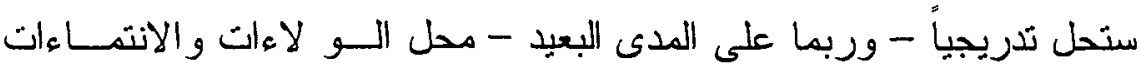

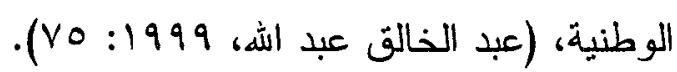
ويرى بعض الباحثين أن العولمة عملية اجتماعية تثوارى فيها القيـود

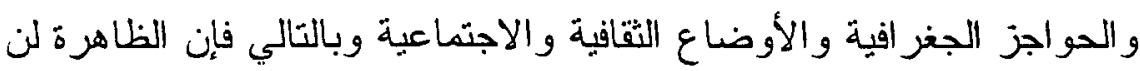
تحدث بصورة مطلقة مرة واحدة، ولكن سوف بتدرج حدوثها مثل المـشاكل التي أخذت صفة العالمية،(Walter,2003). وتشير العولمة في مفهوم علماء الاجنماع إلى حدوث تغير ات بنائية اجتماعية وثقافية تعكس تتامي الاعتمــاد

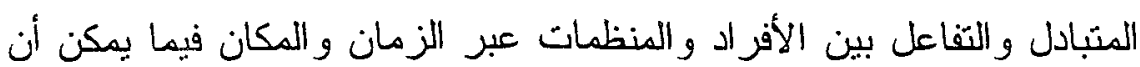
يؤدى إلى "مجنمع عالمي" أو نظام اجتماعي عالمي،(Andrews, 1994). 
وبصفة عامة، يمكن تقسيم مفاهيم العولمة نظرياً إلى نوعين: أولهما

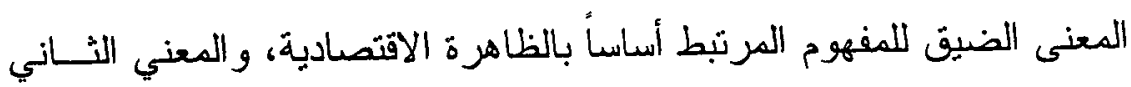

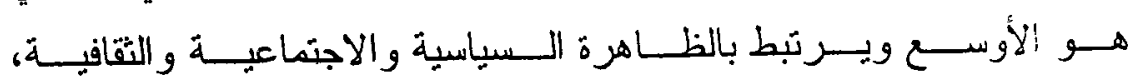

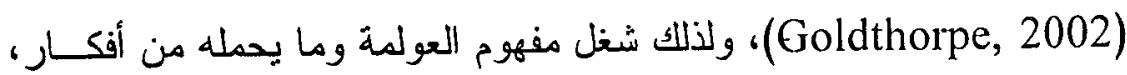
اهنمام كثير من الدول و الحكومات و الشعوب في مختلف مجالاتها الاقتصادية

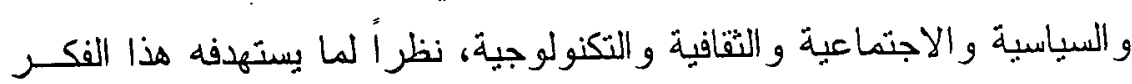

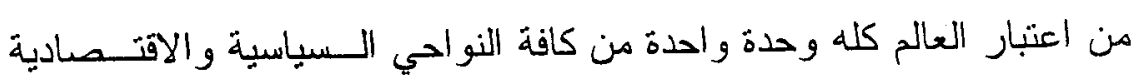

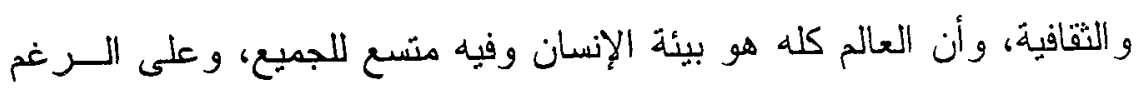

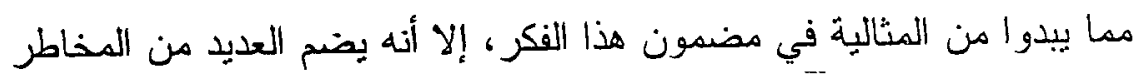

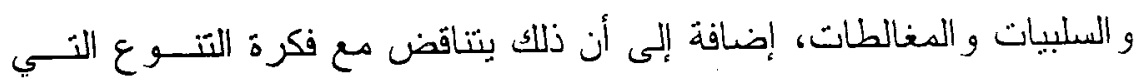

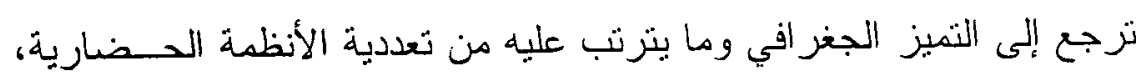

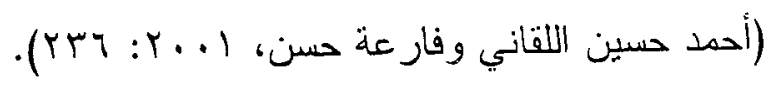

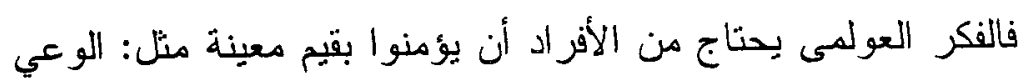

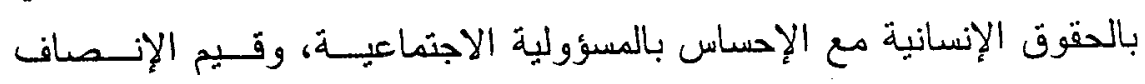

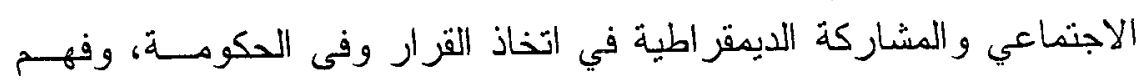

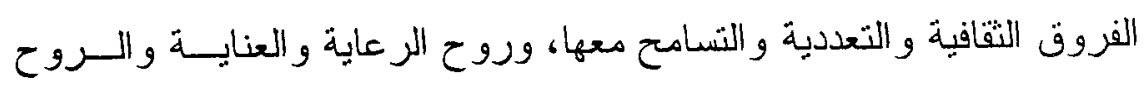

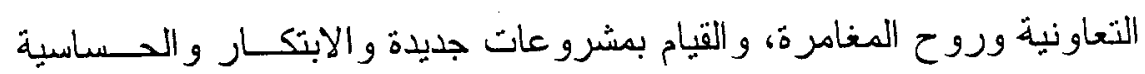

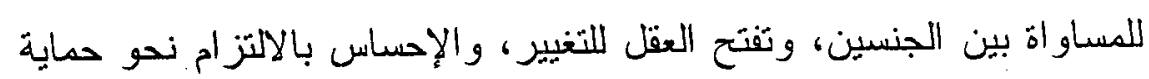

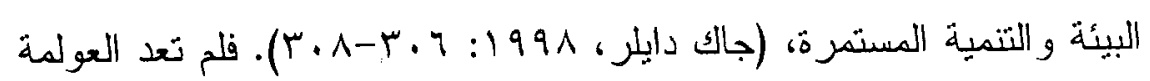

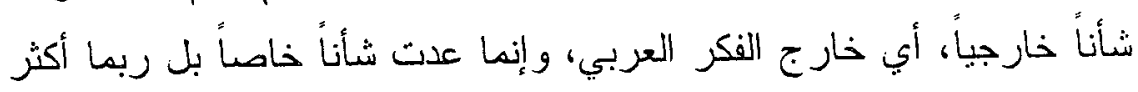

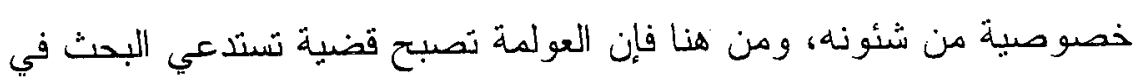

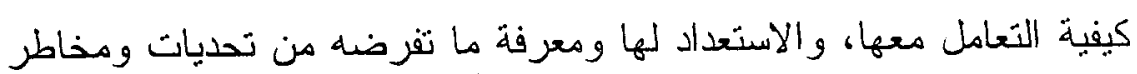

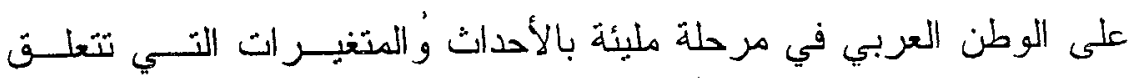


بمستقبل الأوضاع العالمية وخصائصها في القرن الجديد، (إير اهيم العجلوني، . (rTH:) 1999

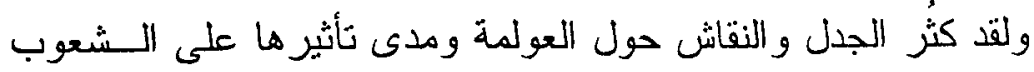

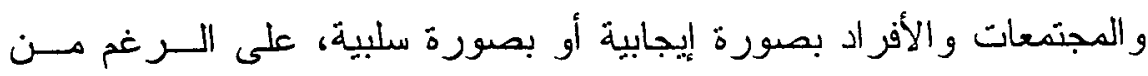

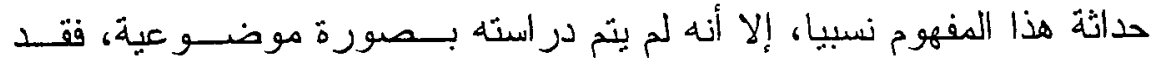

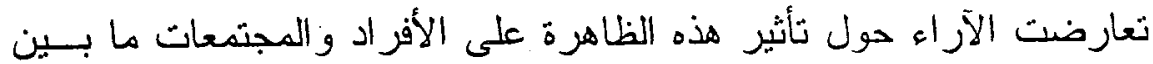
مؤيد ومعارض لها دون الاعتماد على نتائج تجريبية، وقد يرجع ذلك إلـى لـى

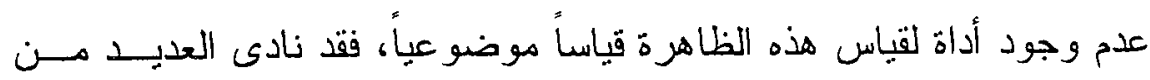

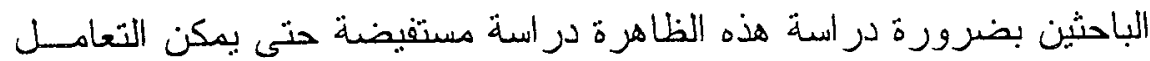

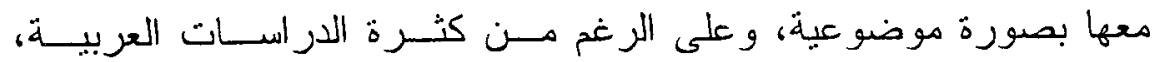
(عبد العزيز النميرات، 19911؛ الحسبن عصمة، 1991 1؛ فؤاد أبو حطـبـ،

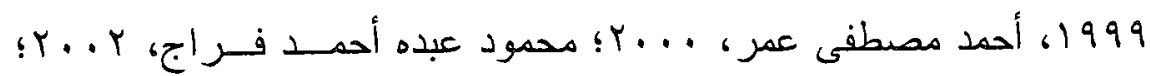

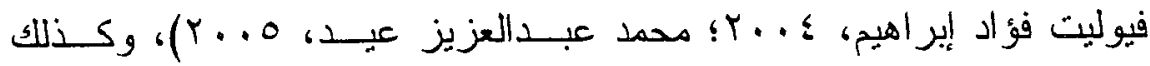

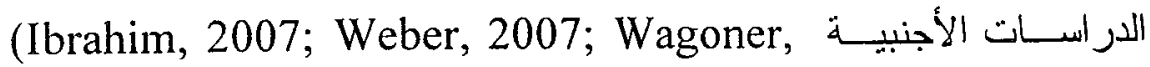
2007; Abdi \& Ellis, 2007; Fox \& Loope, 2007; O'Leary, 2008; Raby, 2008; Ng, 2009; Paredes \& Others, 2009) تتاولت هذا المفهوم إلا أنها لم تتعرض لار استه دراسة كمية سيكومترية من

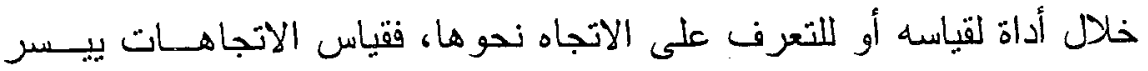

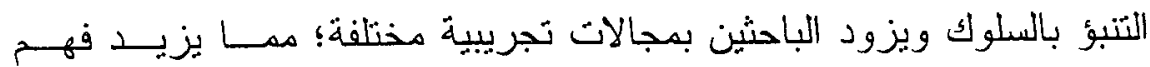

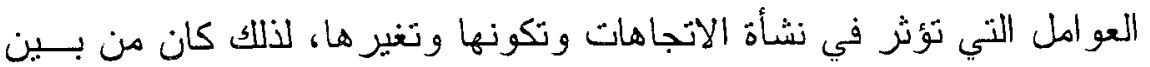
الشروط الهامة لقباس الاتجاهات وضوح موضوع الاتجاه وبساطته، وأهميته

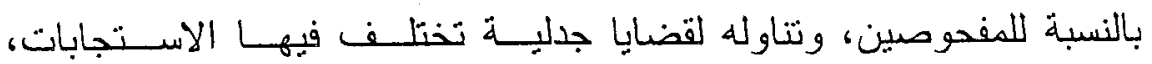

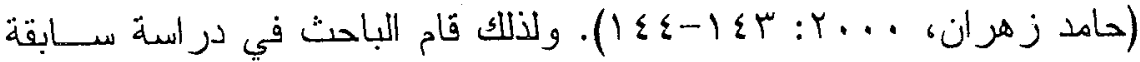


ببحث اتجاهات طالبات الجامعة نحو العولمة (محمد حسين سـعبد، 1 . . Y) وفي هذه الدراسة بتحقق الباحث من مدى صدق وثبات مقياس الاتجاه نحسـو

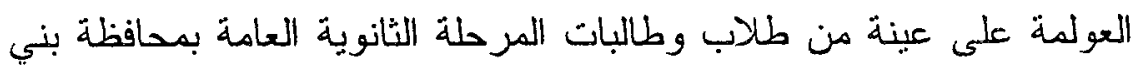
سويف، وذلك من خلال الإجابة عن النساؤل الرئيسي التالي: ما الخصائص

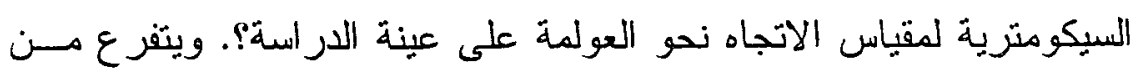
هذا النساؤل الرئيسي النساؤلين التاليين: 1- هل لمقياس الاتجاه نحو العولمة مستوى صدق (الصدق العساملي-

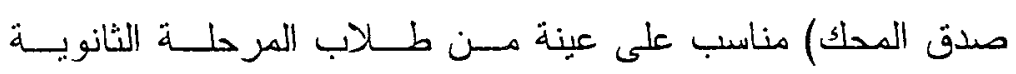
بمحافظة بني سويف؟.

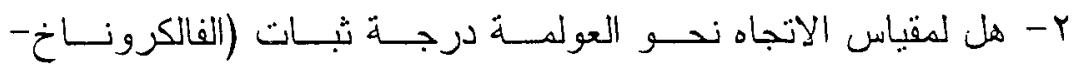

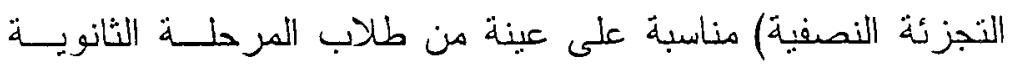

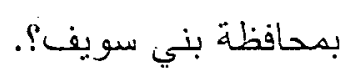

\section{أهداف الدراستة:}

تهدف الار اسة الحالية إلى بحث الخصائص الــسيكومنزية لمقبــاس الاتجاه نحو العولمة على عينة من طلاب وطالبات المرحلة الثانوية بمحافظة

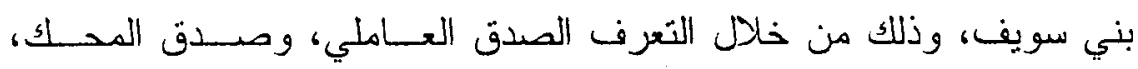

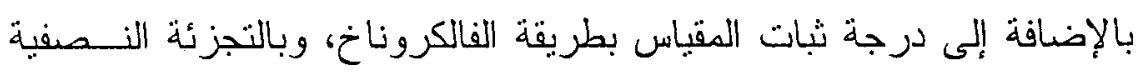

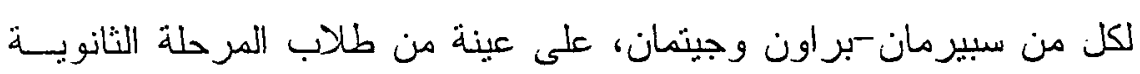
بمحافظة بني سويف.

\section{أهمبة الدراستة:}

ترجع أهمية الدراسة الحالية إلى أهمية القياس في العملية التربويـــة

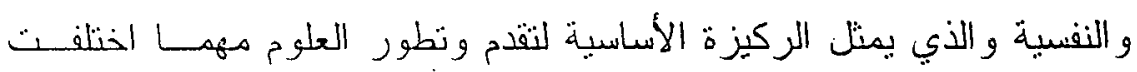


أنواعها وتغيرت أهدافها؛ فهي جميعا تقاس وتقيم بمدى الدقة الني وصل إليها القياس في مجال أبحاثها ودر استها. كما تعتبر قدرة أدوات القياس على قياس ونياس السماث المختلفة بقدر عال من الثبات والصدق وبقدر أقل من الخطأ تعتبـــر من أهم ركائز عملية القياس الصحيح و الدقيق.

ومن ناحية أخرى من الملاحظ أن هنالك نقص في اهتمام البــاحثين

و المتخصصين في القياس و التقويم النفسي والتربوي في العالم العربي بقياس

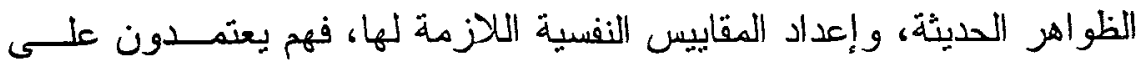
تقتنين أدوات غربية، أو بناء مقاييس في ضوء مقاييس موجودة لقياس نفـس

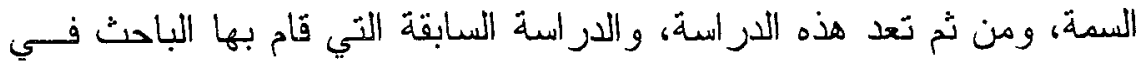
هذا المجال (محمد حسين سعيد، ^ . . Y) من الإضافات في مجال علم النفس بصورة عامة و القياس و النقويم النفسي بصورة خاصة؛ فهي تقــدم مقياســأ لقياس ظاهرة حديثة نسبياً على المستوى العالمي و المحلي وهي العولمة، بما يفتح المجال أمام الباحثين في علم النفس وفي التخصصات الأخرى لار اســة العولمة من جو انبها المختلفة.

\section{مصطلحات الدراسنة:} الخصائص السيكومترية:

باسنعر اض الدراسات و البحــوث الــسابقة التــي اهتمــت بثقـدير

الخصائص السيكومثرية لبعض المقاييس النفسية، Cohen, 1989; Kim, 1990; Dag, 1991; Pons \& Others, 1994; Bikos, 1995; Taylor, 1996; Cook, \& Heppner, 1997; Rohde; 2003; Murray; 2003; Lambert \& Others; 2004; Finney \& Others, 2004; Shek \& Others, 2005; Siu \& Shek, 2005; Lowe \& Reynolds, 2006; Scott \& Others, 2006; Murphy \& Others, 2007; Flessner \& Others, 2007; Papanastasiou \& Angeli, 2008; Bussing \& Others, 2008; Gouveia \& Others, 2009) 


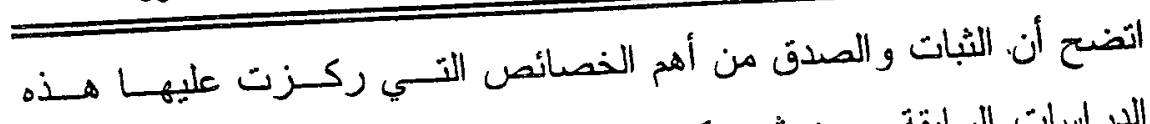

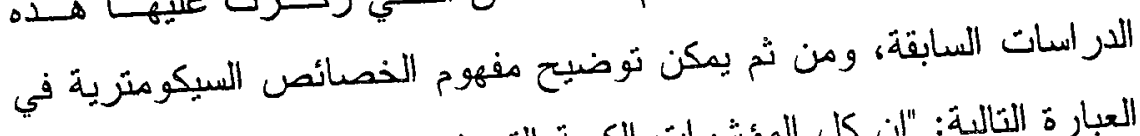

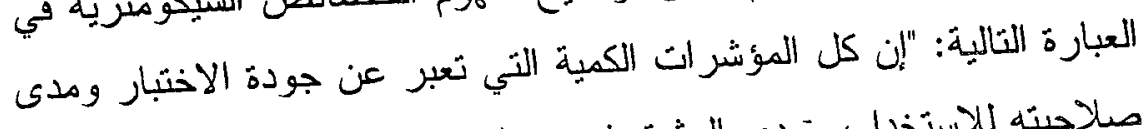

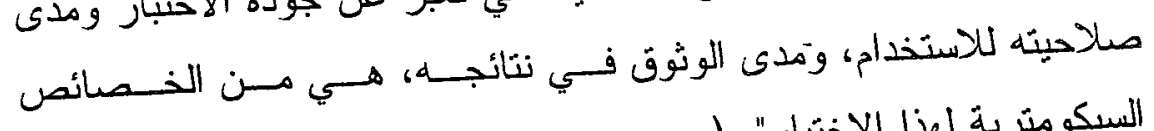

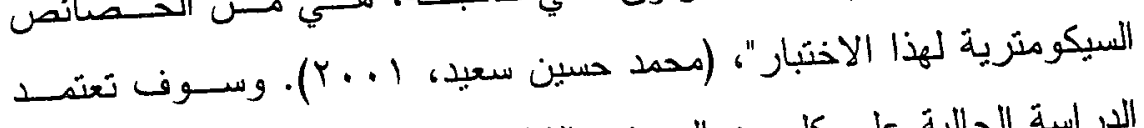

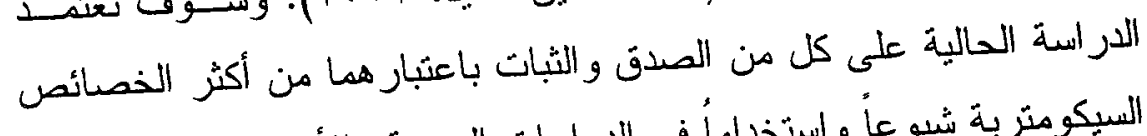
السيكومنزية شيو عاُ و استخدامأ في الدر اسات العربية والأجنبية. الصدق :

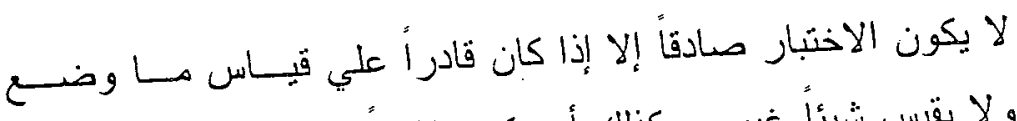

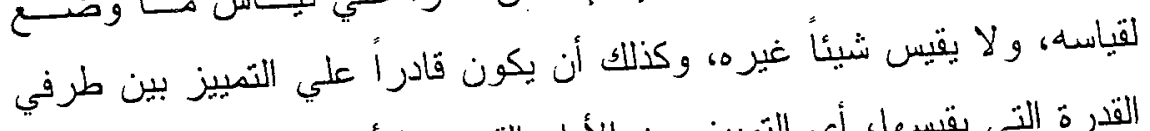

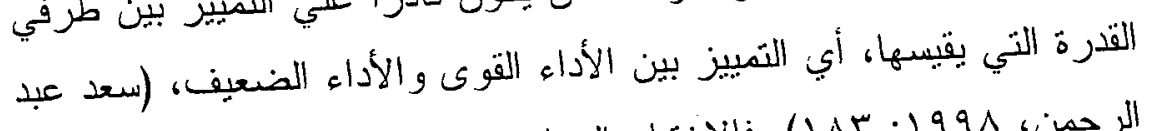

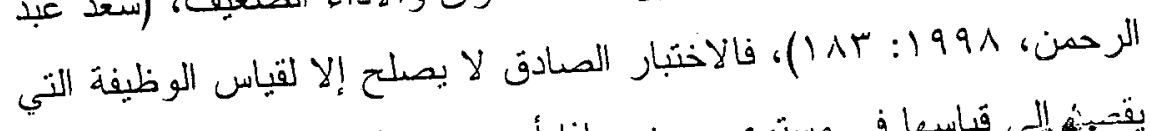

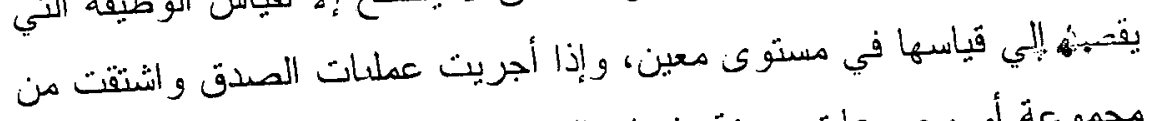

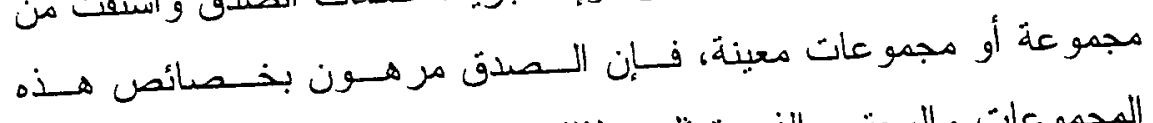

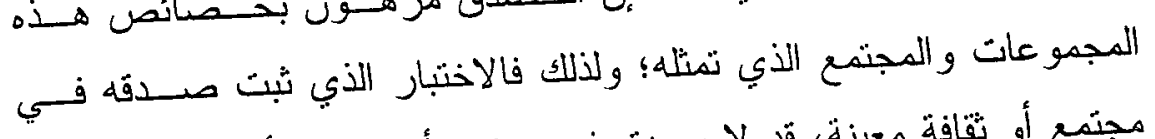

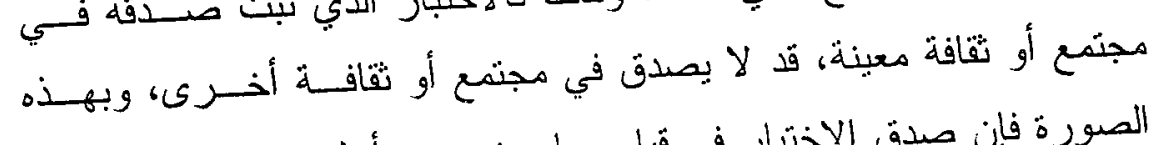

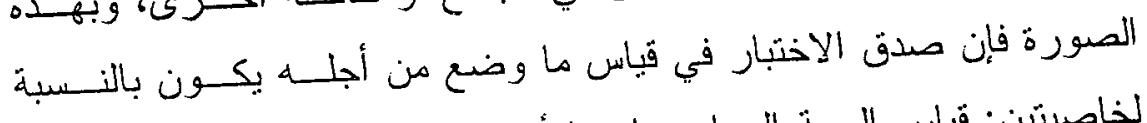

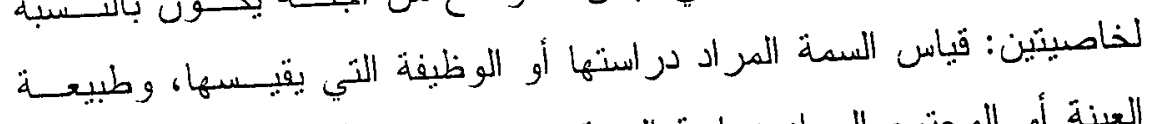

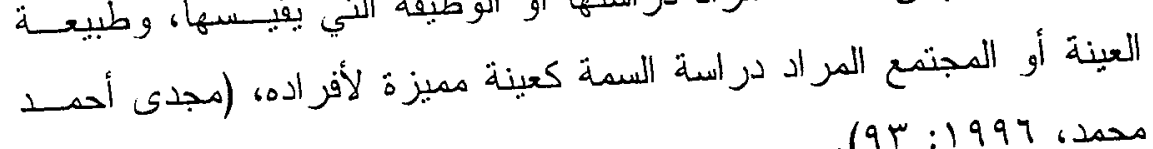

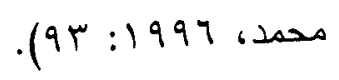

وسوف تستخدم الدر اسة الحالبة طريقة التحليـلـل العــاملي بطريقــة

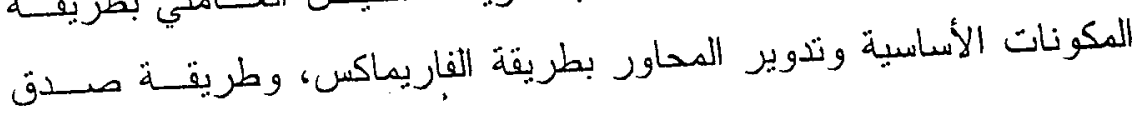


المحك، للتحقق من صدق مقياس الاتجاه نحو العولمة على عينة من طــلاب وطالبات المرحلة الثانوية بمحافظة بني سويف. الثبات:

تتقسم درجة أي فرد في أي اخنبار إلي جزأين: جزء جوهري ثابت

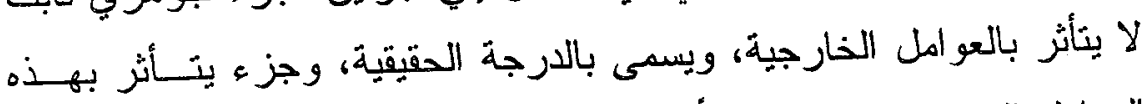

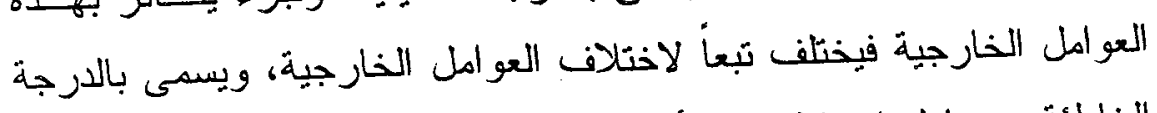

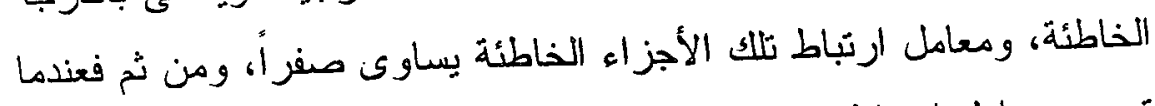

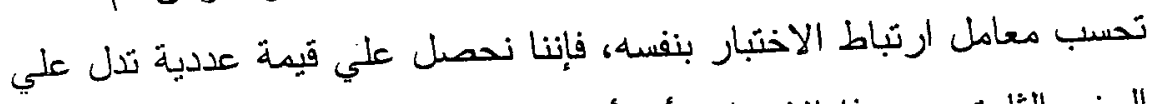

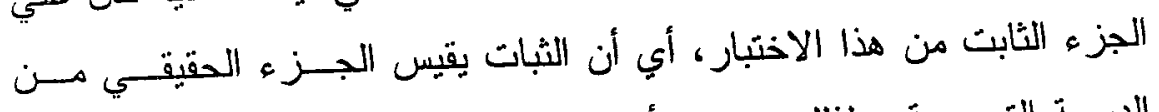

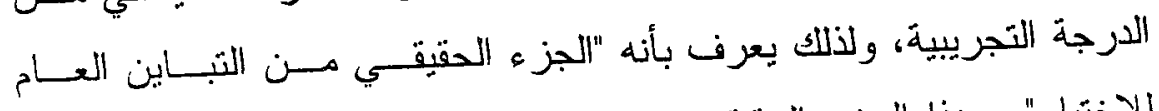

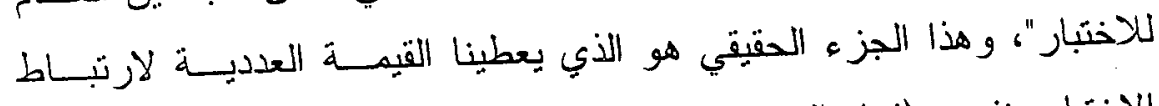

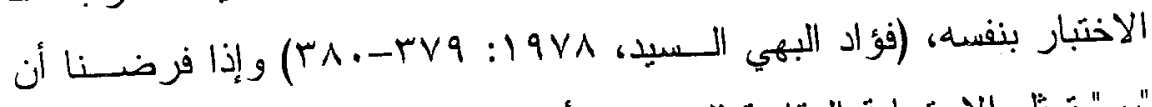

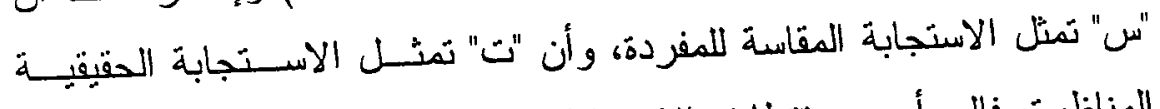

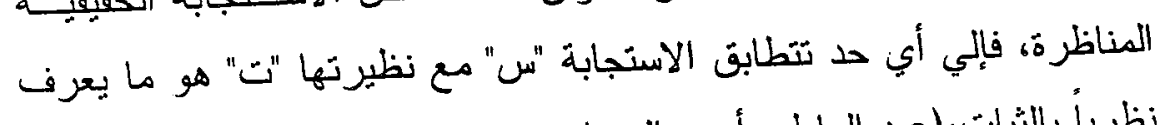

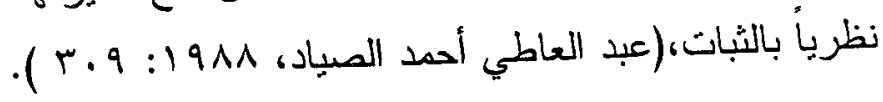

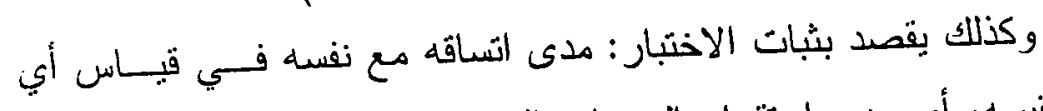

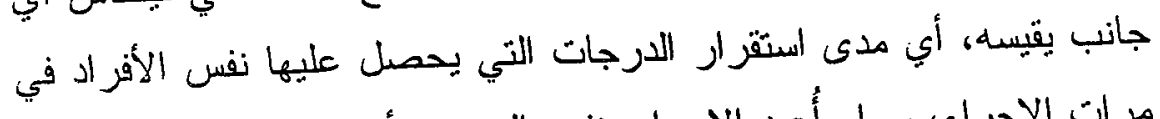

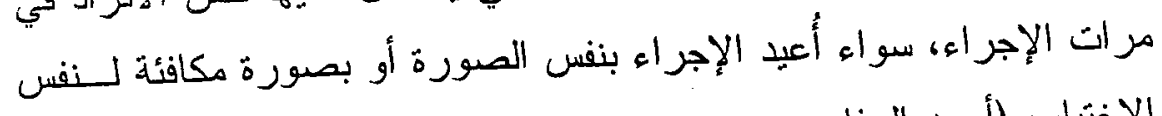

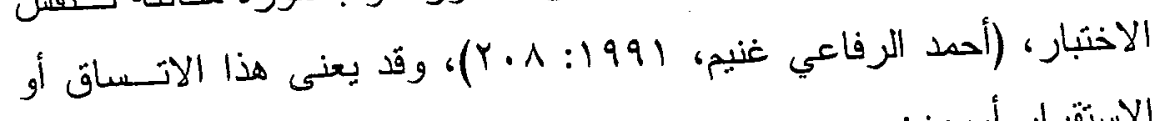

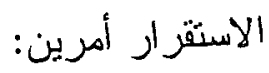
الأول: أن وضع الفرد أو ترتيبه بالنسبة لمجمو عته لا بيتغبر جو هريــا مــن

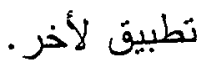


الثاني: أنذه لو تكررت عمليات القياس للفرد الواحد لظهرت صفة الاســترار في "رجيته في المرات المختلفة. وبذلك يمكن القول بأن: ثبات الاختبار يعنى

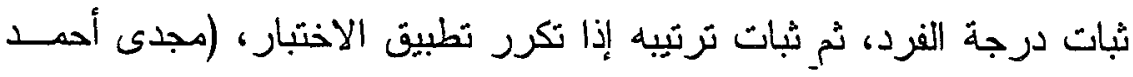

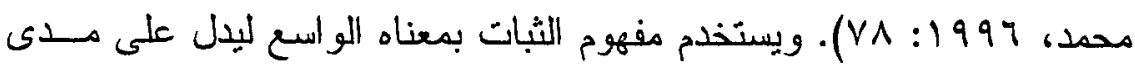

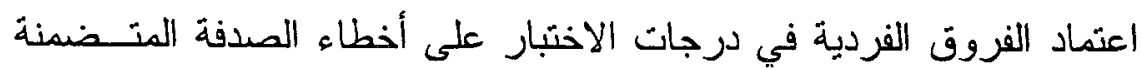

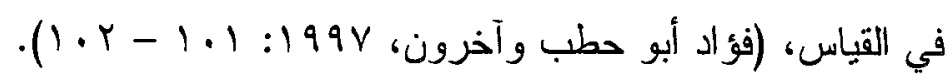
وسوف تعتمد الدراسة الحالية على طربقة ألفا لكرونباخ و التجزئسة النصفية لسبيرمان براون وجيتمان في تقدير الثبات لمقياس الاتجــاه نحسو العولمة على عينة من طلاب وطالبات المرحلة الثانوية بمحافظة بني سويف. الآجهاه: الاتجاه عبارة عن عملية تقويم أحد موضوعات التفكير والتي تمثـلـ

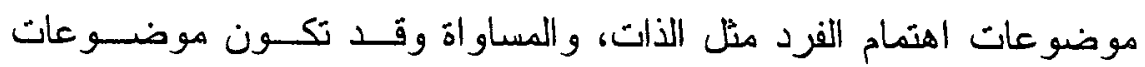
الاهنمام عيانية مثل شخص مألوف، وقد نكون مركبة ومجردة مثل الإنسانية

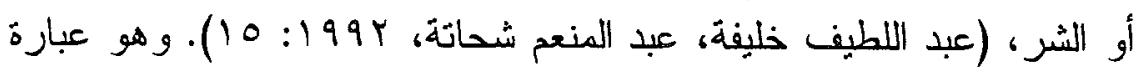
عن نسق، أو تنظيم له مكونات ثلاثة: معرفية Cognitive تثضمن المعارف

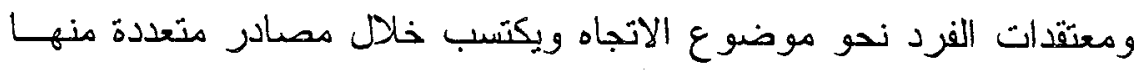

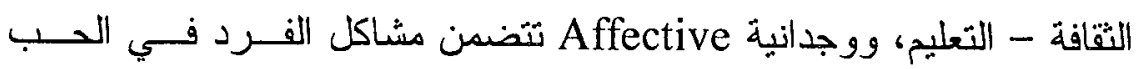

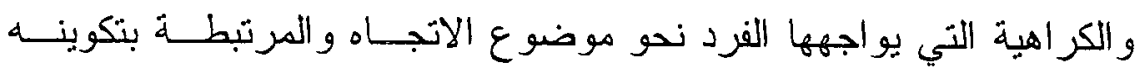

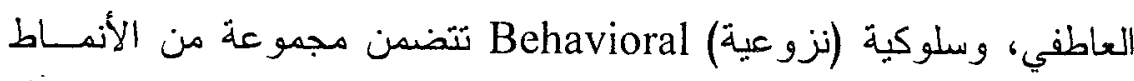

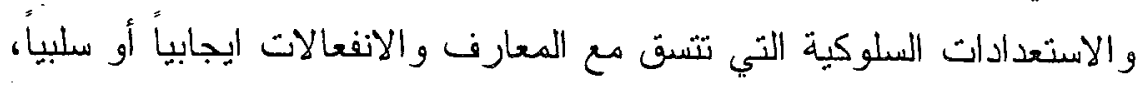
فهي تدفعه إلى العمل على نحو ايجابي عندما يمثلك اتجاهات ايجابية ندهـو بعض المو اضيع، وتدفعه إلى العمل على نحو سلبي إذا كان بحمل اتجاهـات التهات

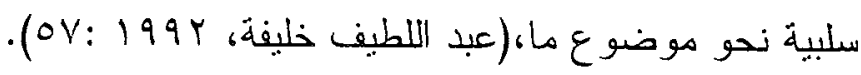


ويعرف الاتجاه بأنه ميل ثابت للتصرف والاستجابة بطريفة معينة مع

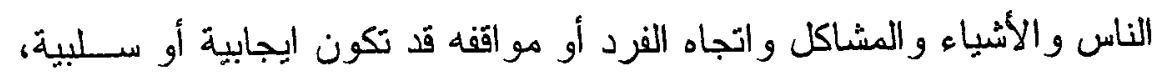

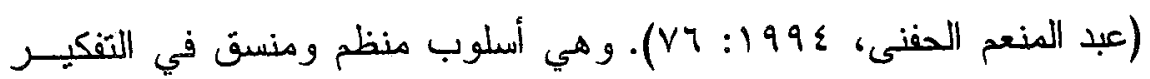

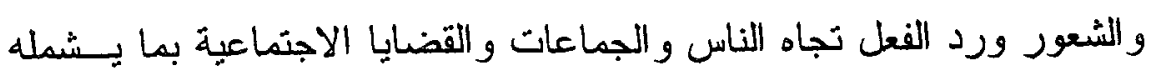

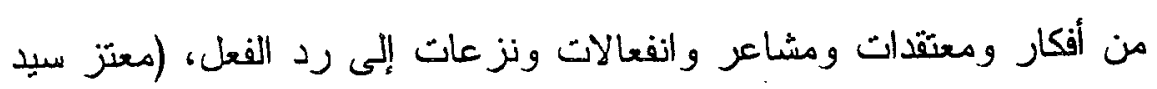

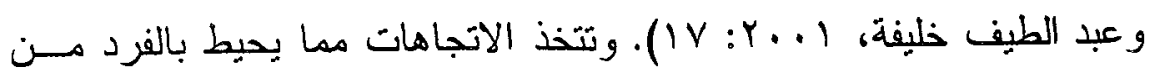

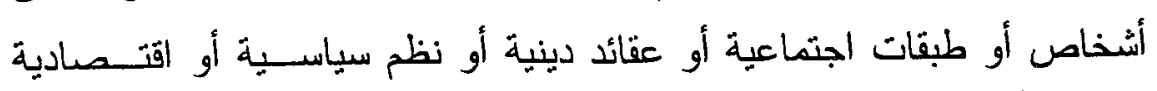

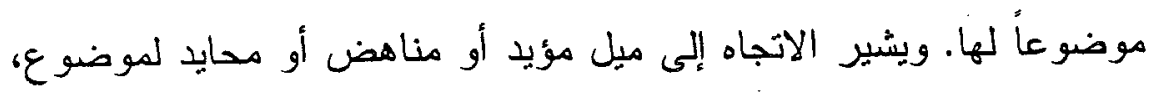

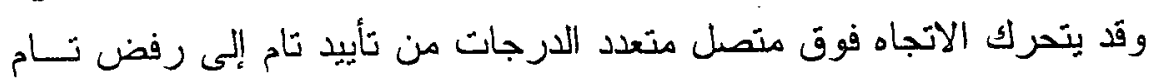

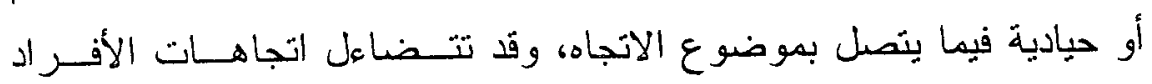
وتتمركز حول عالمه الضيق فقط حبث أسرته ومشاكله و التوحد مع اتجاهاتها

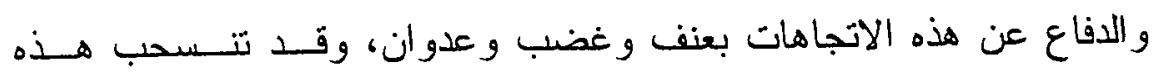

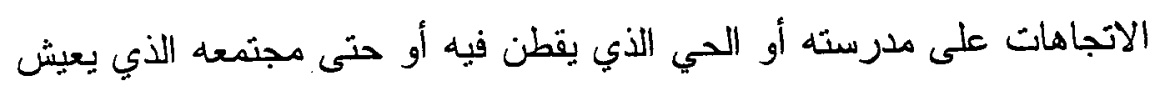

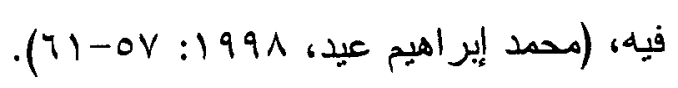

و هو حالة من الاستعداد العقلي و العصبي انتظمت من خلال الخبـــرة

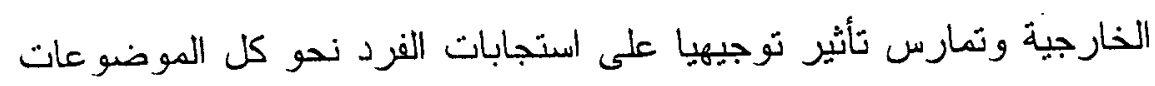

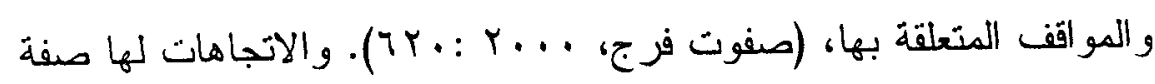

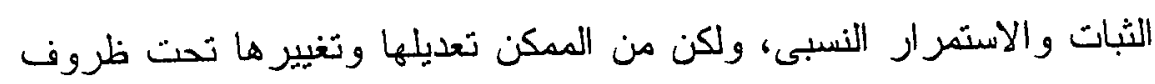

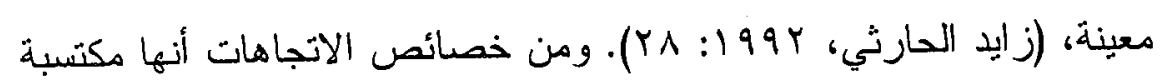

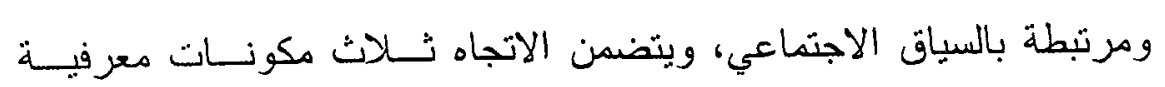

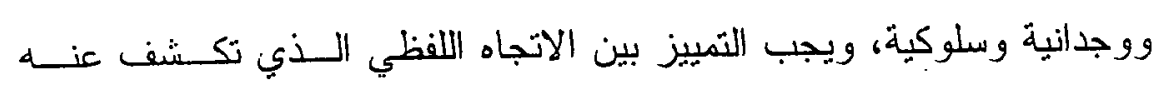

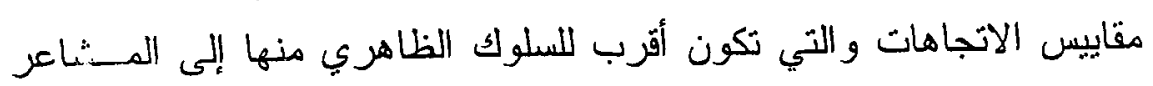

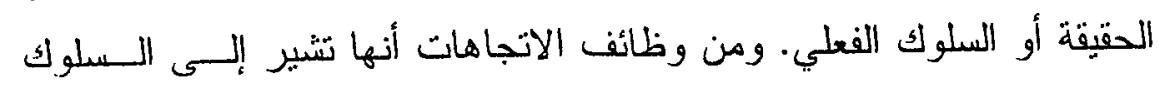


وتفسره من خلال تنظيم العمليات الافاعية والانفعالية و الإدر اكية و المعرفية، كما تيسر اللفرد القدرة على السلوك واتخاذ القرارات بقدر من الاتساق فـي ولئي

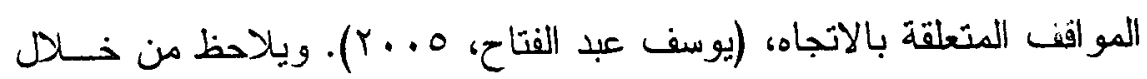

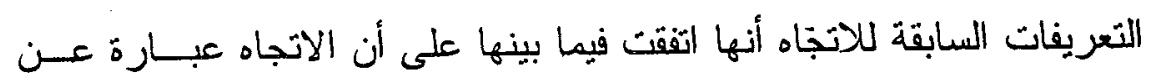

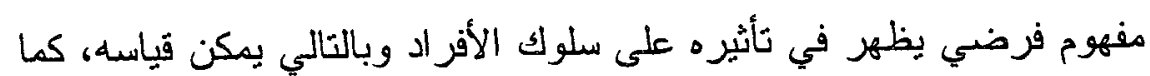

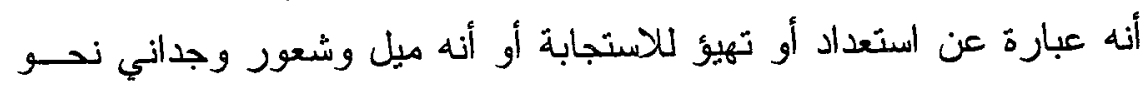

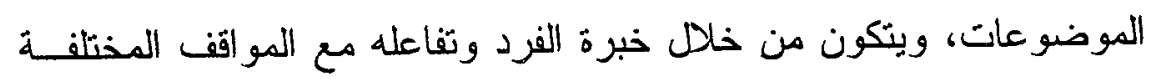

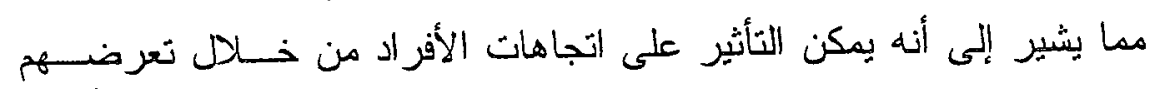
لخبر ات معبنة. العولمة:

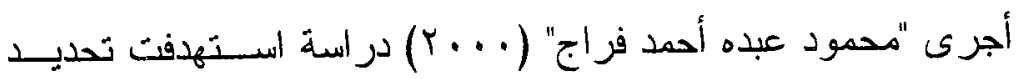

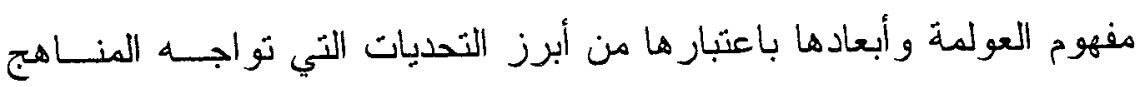

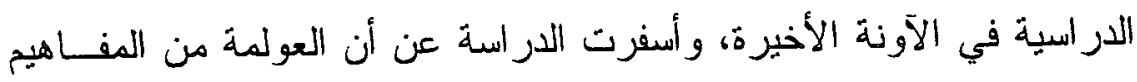

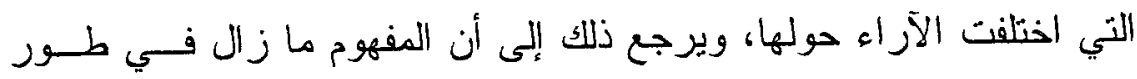

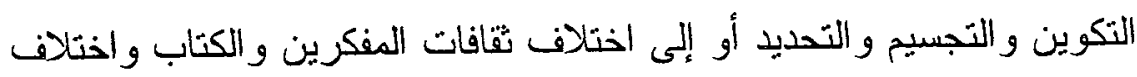

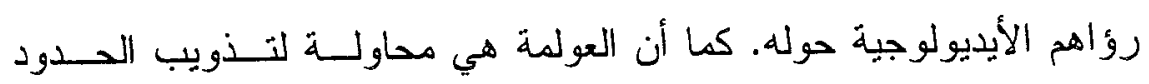

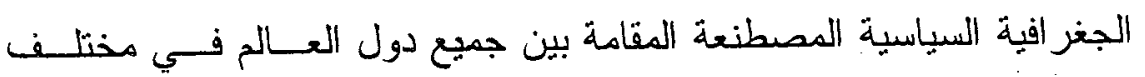

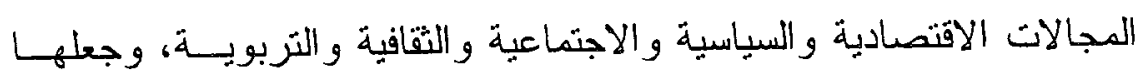
عالماً و احداً، يخضع في مختلف مجالاته لسوق واحد. و أصبحت تأخذ أشكالاً عدة منها: العولمة الاقتصادية والسياسية والاجنماعية و النقافية.

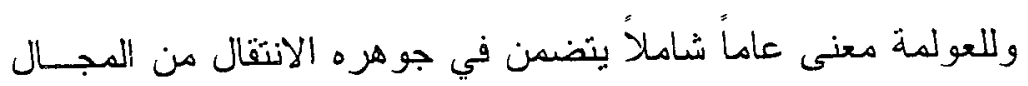

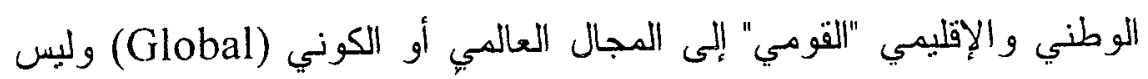
الدولي (International) فالأخيرة تعني وجود حدود وخطوط الفصل، بينما 
الأولى تعني تجاوز الحدود وزو الها، وبعبازة أخرى اللاحدود، وهذه اللاحدود

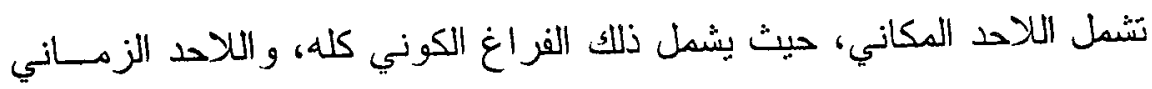

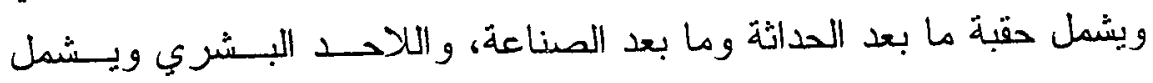

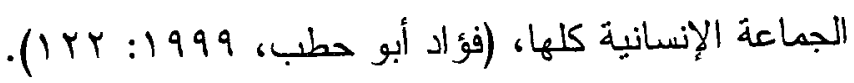

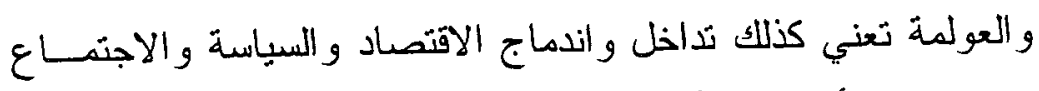

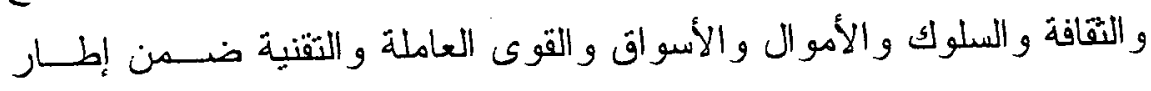

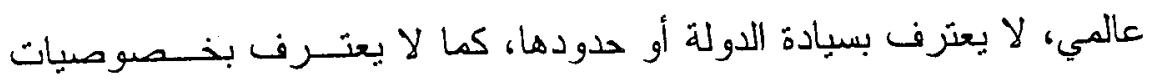

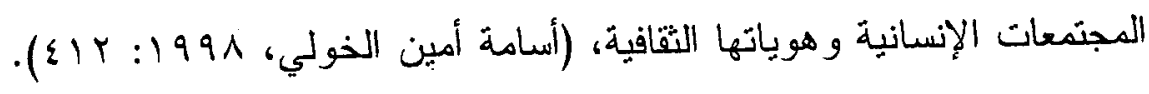

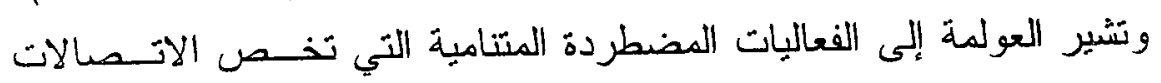

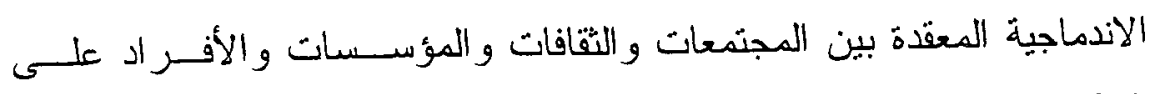
النطاق العالمي، فالعولمة هي الحركة الاجتماعية التي تضمن انكماش البعدين

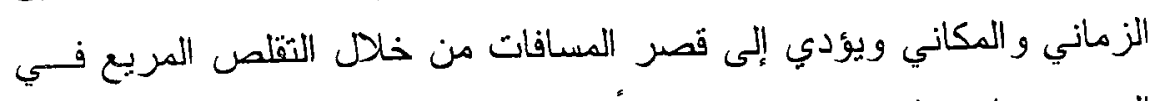

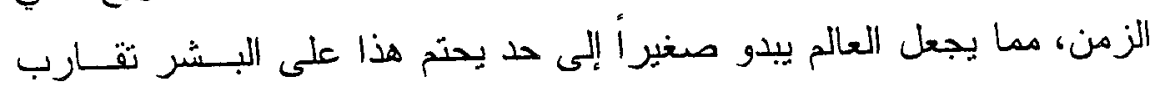
بعضهم مع بعض، (Tomlison, 1991).

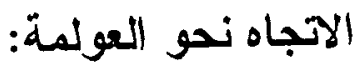

الاتجاه هو ميل ينجه بالسلوك قريباً هن بعض عو امل البيئة أو بعيداً

عنها، فيضفي عليها معايير موجبة أو سالبة، تبعاً للانجذاب نحو ها أو النفور

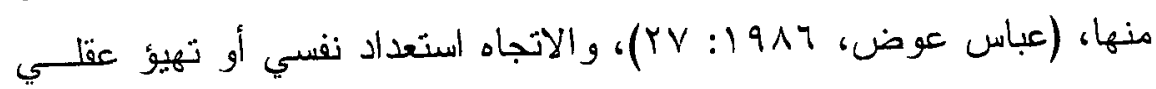

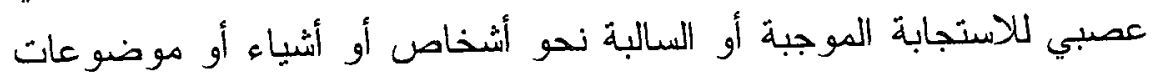

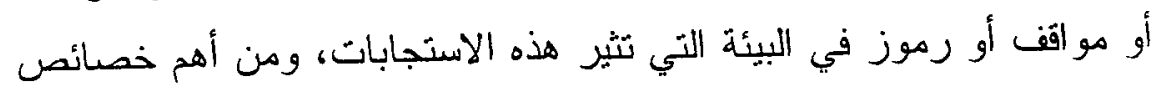

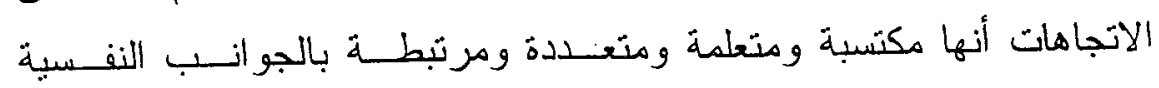

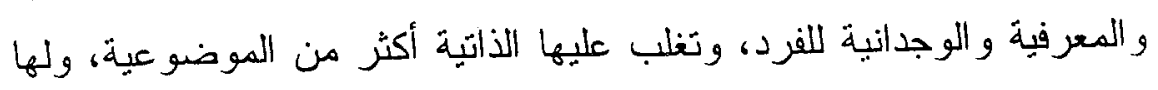


صفة الثبات النسبي لكن من الممكن تعلمها وتغيير ها، (محمود عبــد الحلــيم منسي، (199). (19).

ومن خلال التعريفات المختلفة للعولمة، ومفهوم الاتجاه فإن الباحسـث

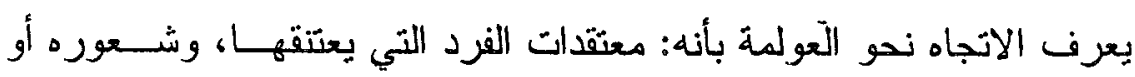

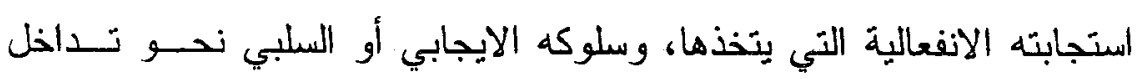

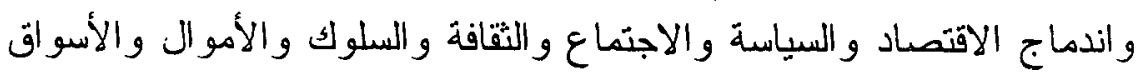

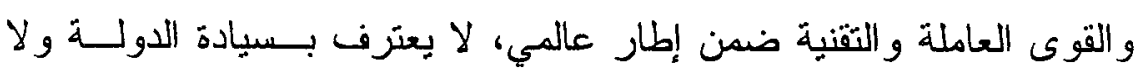
بحدودها، كما لا بعترف بخصوصيات المجتمعات الإنسانية وهوياتها الثقافية.

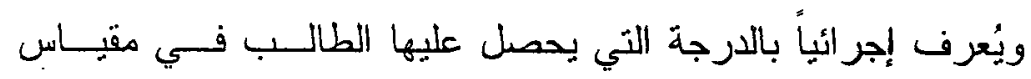
الاتجاه نحو العولمة المستخدم في الدر اسة الحالية.

\section{الدراساتد السبابقة:}

لقد نالت العولمة اهنمام العديد من الباحثين على مختلف تخصصاتهم،

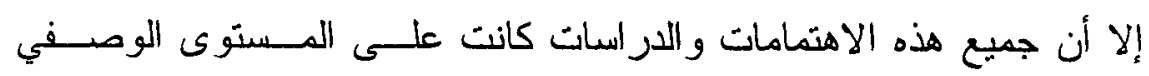

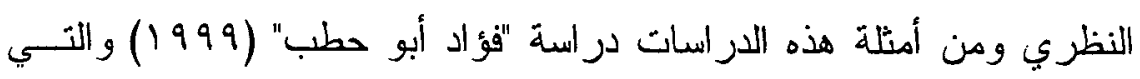

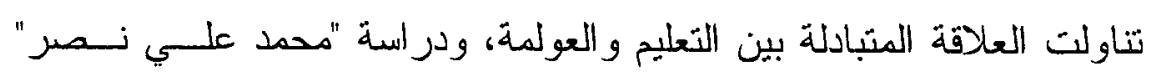

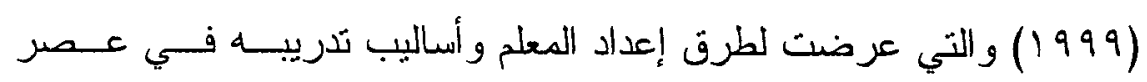

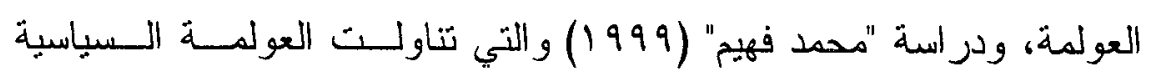
وحقوق الإنسان، ودراسة "محمد عباس إيراهيم" (999 (199) و التي بحثت الثقافة

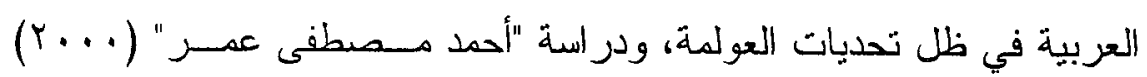

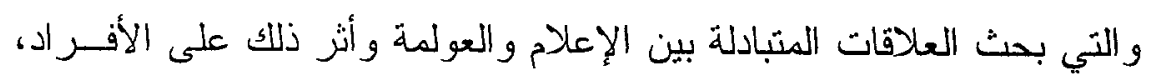

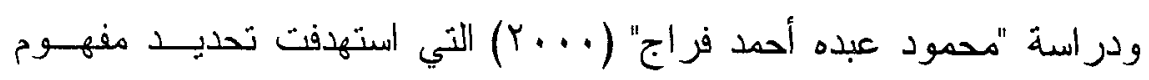

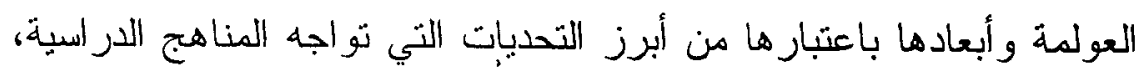

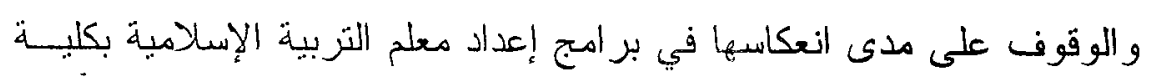




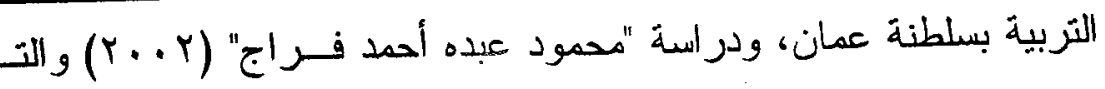
هدفت إلى إعداد برنامج في الثقافة الإسلامية في تتمبة القيم لمو اجهة تحديات

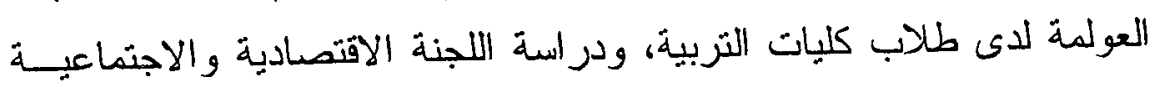

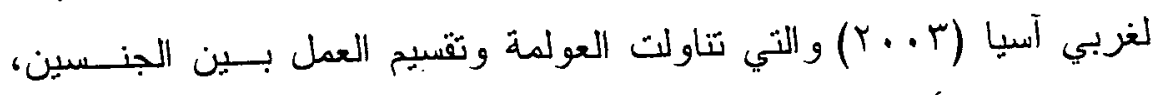

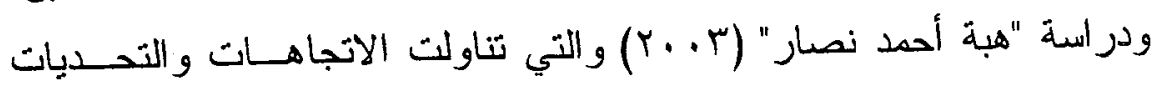

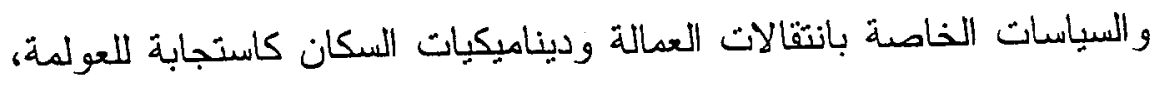

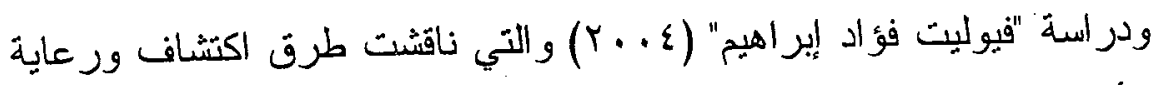

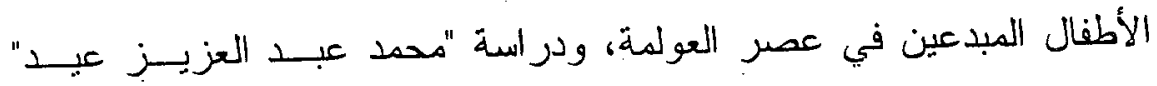

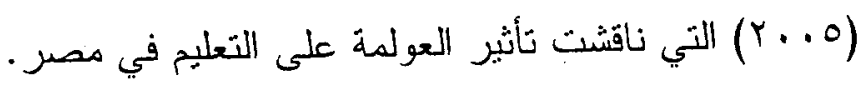

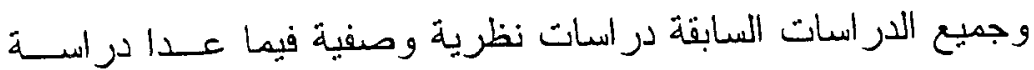

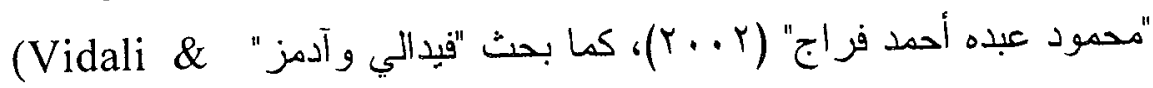
Adams, 2006)

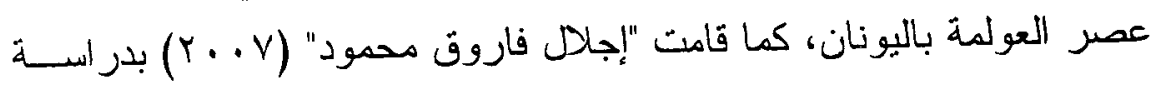

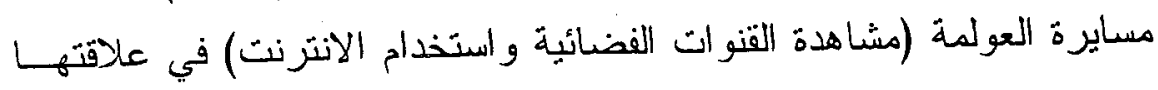

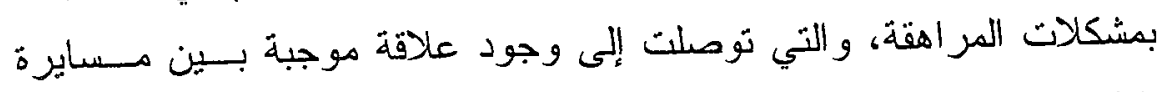

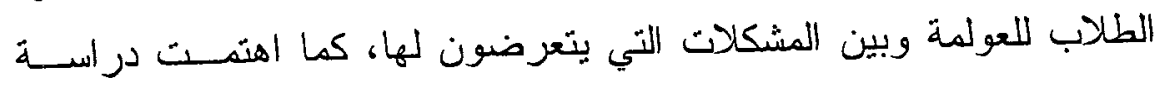

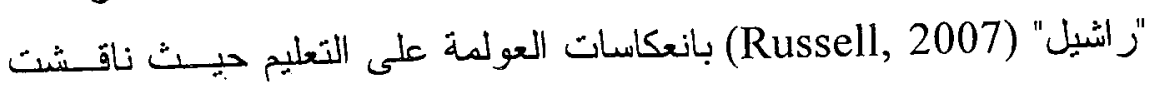
التعليم عن بعد Distance Education كأحد أهم المنطلبات لنطوير التعليم في ظل ثقافة العولمة، وركزت در اسة "سترومكست" (Stromquist, 2007) على مناقشة مفهوم الدولية Internationalization في مقابل مفهوم العولمة

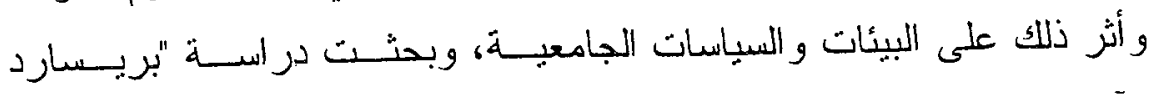
و آخرون" (Brisard \& Others, 2007) السياسات التربوية المتعلقة بالمعلم

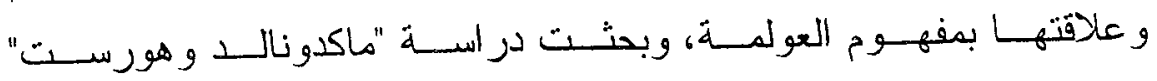


تحيز المناهج في ظل العولمة وأثر ذلك (McDonald \& Horst; 2007)

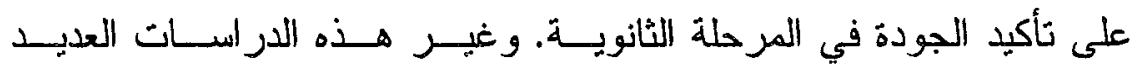
(Bottery, 2006; Hawisher \& Others, 2006; Ibrahim, 2007; Weber, 2007; Wagoner, 2007; Abdi \& Ellis, 2007; Fox \& Loope, 2007; Milner, 2007; Huilan, 2007; Milliron, 2007; Wu \& Others, 2008; Engel \& Rutkowski, 2008; Ng, 2009) و التي تتاولت العولمة من الناحية الوصفية النظرية ولم تتعرض اللعولمة من حيث القياس النفسي الكمي. إلا أن الباحث في دراسة سابقة له (محمد حسين

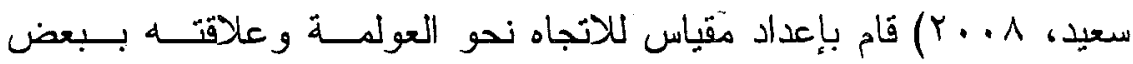
المتغير ات لدى طالبات الجامعة، وقد أظهرت نتائج الدراسة عدم وجود فروق دالة إحصائياً نرجع إلى التخصص و الموقع الجغر افي في الاتجاه نحو العولمة

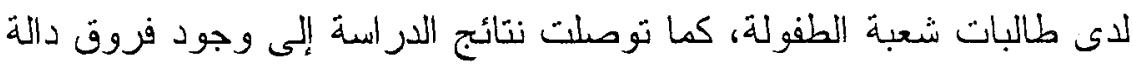
إحصائياً بين مرتفعات ومنخفضات الاتجاه نحو العولمة في كل من: دافعيــة

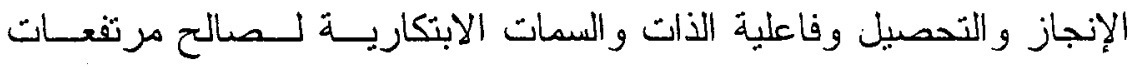

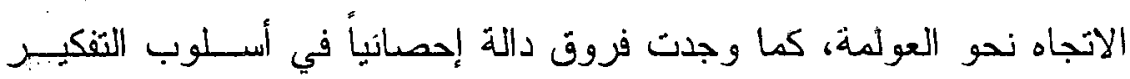

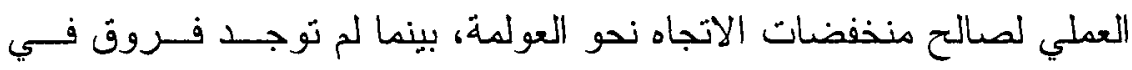

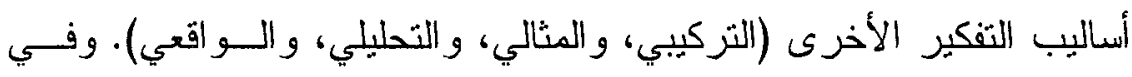

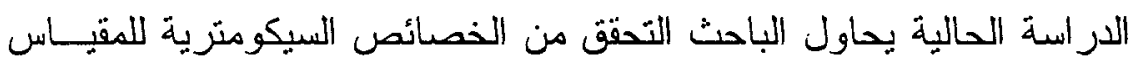
على عبية من طلاب وطالبات المرحلة الثانوية بمحافظة بني سويف. فروض الدراسنة: بمكن صياغة فروض الدراسة الحالية على النحو التالي:

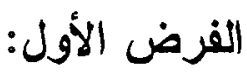

يتمتع مقياس الاتجاه نحو العولمة المستخدم فــي الدر الســـة الحاليــة بمستوى صدق مناسب. 
ينمنع مثياس الاتجاه نحو العولمة المستخدم فــي الدر اســـة الحاليــة

$$
\begin{aligned}
& \text { بدرجة من الثبات مناسبة. } \\
& \text { إجراءات الدراسةة: } \\
& \text { أولاً: منهج الدراسة: }
\end{aligned}
$$

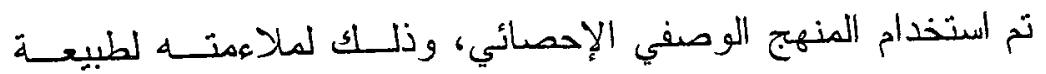
وأهداف الدراسة، التي تحاول التعرف على الخصائص السيكومترية لمقباس الاتجاه نحو العولمة من خلال التأكد من صدقه وثباته على عينة الدر اسة. ثانياً: عينة الدر اسةة: العاه

اشتملت عبنة الدر اسة على (orv) طالباً وطالبةًة من الـصف الأول الثانوي، تم اختيار هم من بعض المدارس الثانوية العامة بمحافظة بني سويف

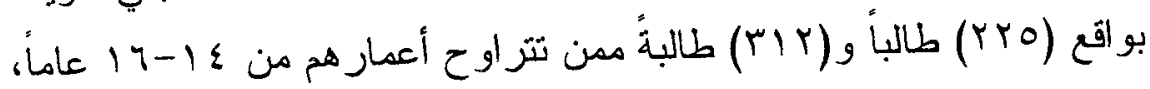
وذلك بالمر اكز التالية: أهناسيا المدينة، وبنى سويف، وببا، وبوش. ويوضح

\begin{tabular}{|c|c|c|c|}
\hline المجموع & إناث & ذكور & العينة \\
\hline $1 \varepsilon \varepsilon$ & $\wedge 7$ & $0 \wedge$ & إهناسيا \\
\hline 10. & 95 & $O V$ & بني سويف \\
\hline IrV & V9 & $0 \wedge$ & ببا \\
\hline 1.7 & of & Or & بوش \\
\hline orv & MIr & YYo & المجموع \\
\hline
\end{tabular}
الجدول التالي توزيع عينة الدر اسة وفقاً للمركز و الجنس (ذكور -إناث).

$$
\text { جلول (1) }
$$




\section{تالثًا: أدوات الدراسة:}

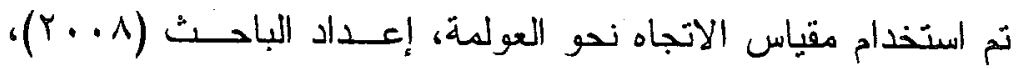

ويتكون المقياس من (Yr) عبارة من نوع ليكرت خماسي، أمام كل عبـارة

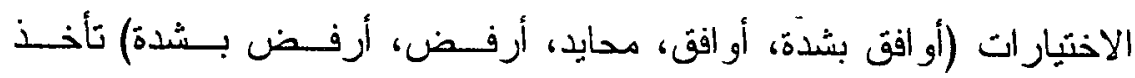

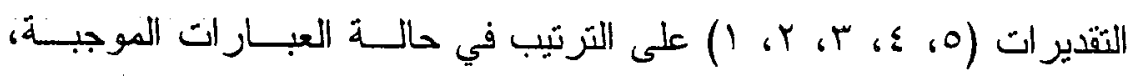

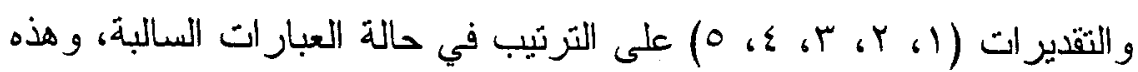

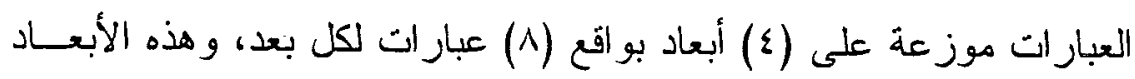

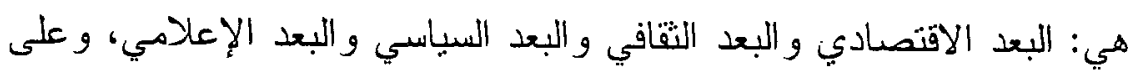

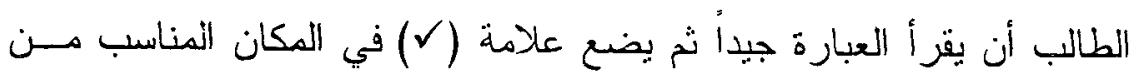

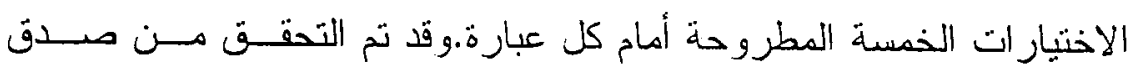

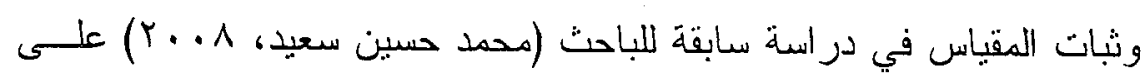

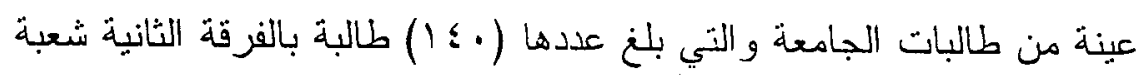

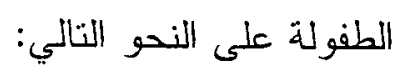

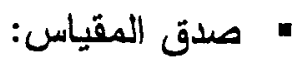

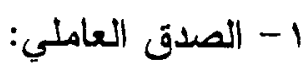
تم استخدام الصدق العاملي باستخدام طريقة المكونــات الأساسـبـة،

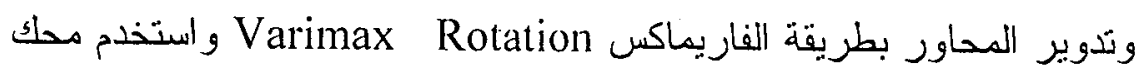

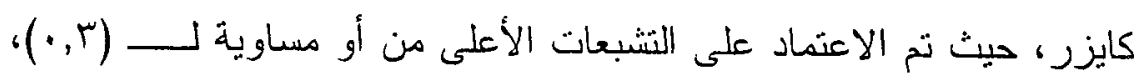

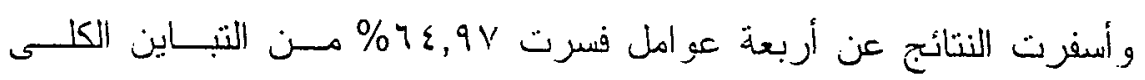

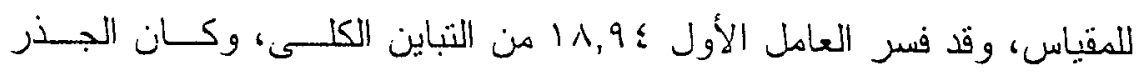

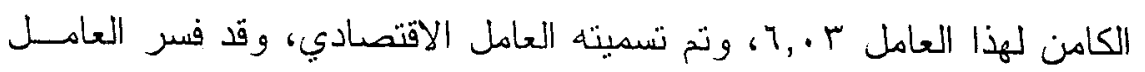

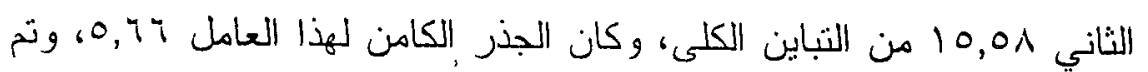

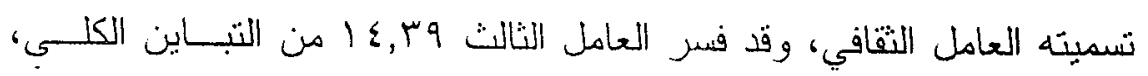


وكان الجذر الكامن لهذا العامل I|, Ir، وتم تسميته العامل السياسي، وقد فسر

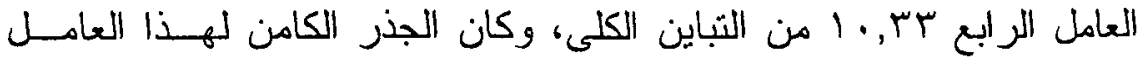

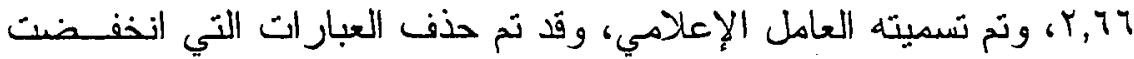

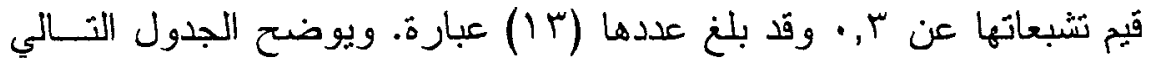
قيم تشبعات المفردات (بعد حذف العبار ات غير الدالة) بعد التدوير . جدول (r)

تشبعات المفردات على العو امل لمقباس الاتجاه نحو العولمة بعد التدوير

\begin{tabular}{|c|c|c|c|c|}
\hline الإعلامي & السياسي & التقافلي & الاقتصادي & العبارات \\
\hline$\cdot, \backslash \wedge \varepsilon$ &., $0 \vee 7$ & $\cdot, 7 \varepsilon$. &., $0 Y T$ & 1 \\
\hline$\cdot, \varepsilon \wedge \wedge$ &., 099 & $\cdot, 271$ & $\cdot, \varepsilon \varepsilon \varepsilon$ & Y \\
\hline$\cdot, \Sigma \wedge \uparrow$ &., $71 \mathrm{~V}$ &., 0.1 &., $0 Y T$ & $r$ \\
\hline - , VYq & $\cdot, 7 \vee 7$ & $\cdot, \Gamma \leqslant T$ &., 019 & $\varepsilon$ \\
\hline., 041 & $\varepsilon Y Y$. &., 010 & $\cdot, 770$ & 0 \\
\hline$\cdot, \varepsilon \mid r$ & $\cdot, \varepsilon \leqslant \varepsilon$ & $\cdot, \Sigma Y \wedge$ & $\cdot, 7 \leqslant V$ & $y$ \\
\hline$\cdot, \varepsilon \backslash 1$ &., $0 \leqslant 1$ & $\cdot, 71 \mathrm{~V}$ & .0 .1 & V \\
\hline$\cdot, \sum 17$ & $\cdot, 0.5$ & $\cdot, \varepsilon \leqslant \wedge$ &., 09 . & $\Lambda$ \\
\hline
\end{tabular}

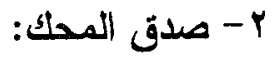

حيث بلغت قيمة معامل الارتباط بين مقياس رتب الهوية إعداد "محمد السيد عبدالرحمن" (1991) وبين درجات الطالبات على مقياس الاتجاه نحو

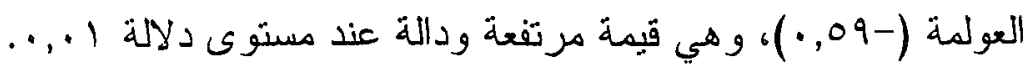
ثبات المقياس:

تم استخدام طريقة ألفا لكرونباخ و التجزئة النصفية بطريقة سبيرمان براون وجينمان لتقدير معامل ثبات أبعاد المقياس، ويوضح الجدول التـالي نتائج ذلك. 
جدول (r) معاملات ثبات أبعاد مقياس الاتجاه نحو العولمة

بطريقة ألفا لكرونباخ و التجزئة النصفية

\begin{tabular}{|c|c|c|c|}
\hline \multicolumn{2}{|c|}{ التجزنة النصفية } & \multirow{2}{*}{ معامل ألفا } & \multirow{2}{*}{ الأبعاد } \\
\hline جيتمان & سبيرمان & & \\
\hline$\cdot, \wedge \varepsilon$ & $\cdot, \wedge \varepsilon$ & $\cdot$, , & البعد الاقتصادي \\
\hline$\cdot, \wedge \mathrm{T}$ & $\cdot, \wedge 0$ & $\cdot, \wedge \varepsilon$ & البعد الثقافي \\
\hline$\cdot, \wedge$. & $\therefore, \Lambda$. & $\cdot, \wedge 1$ & البعد السياسي \\
\hline$\cdot, \wedge 7$ & $\cdot, \wedge 7$ & $\cdot, 10$ & البعد الإعلامي \\
\hline
\end{tabular}

كما تم تقدير معامل الارتباط بين درجة كل مفردة و الارجة الكليــة

للبعد الذي تتنمي إليه، وقد كانت جميعها قيم مرتفعة ودالة عند مسنوى دلالة

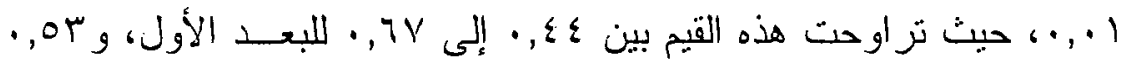

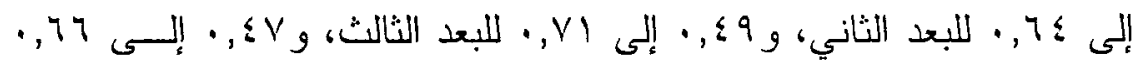

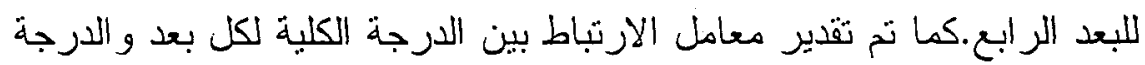

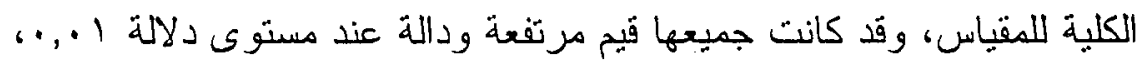
ويوضح ذلك الجدول التالي. جدول (ع) معامل الارتباط بين الدرجة الكلية لكل بعد و الدرجة الكلية لمقياس الاتجاه نحو العولمة

\begin{tabular}{|c|c|}
\hline معامل الارتباط & الأبعاد الأساسية \\
\hline$\cdot, \wedge 4$ & البعد الاقتصادي \\
\hline$\cdot, \wedge T$ & البعد الثقافي \\
\hline$\cdot, \wedge Y$ & البعد السباسي \\
\hline$\cdot, \wedge 0$ & البعد الإعلامى \\
\hline
\end{tabular}

رابعاً: خطوات الدراسة:

للإججابة عن تساؤلات الدراسة و التحقق من فروضها تم القيام بالعديد من

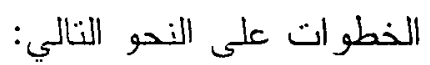


• مر اجعة الإطار النظري و الدراسات السابقة المرتبطة بموضوع الدر اسة. - تطبيق مقياس الاتجاه نحو العولمة ومقياس رثب الهوية على عينة الدراسة. " جمع وتبويب البيانات وتحليلها بالأساليب الإحصائية المناسبة. • التوصل إلى نتائج البحث ومناقشتها وتقديم التوصيات والمفترحات. خامساً: المعالجة الإحصائية لبيانات الار اسة:

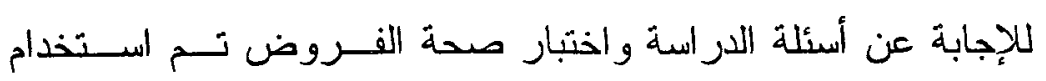

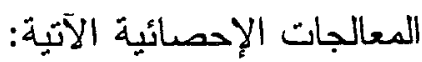
1- التحليل العاملي بطريقة المكونات الأساسية وتدوير المحسـاور بطريقــة الفاريماكس:

اللتعرف على طائفية كل عامل استخدم مخك جيلفورد لالالة التشبع على

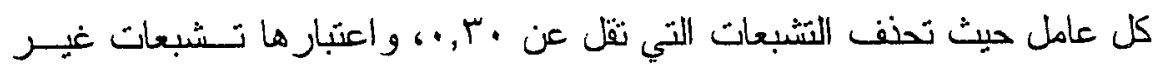

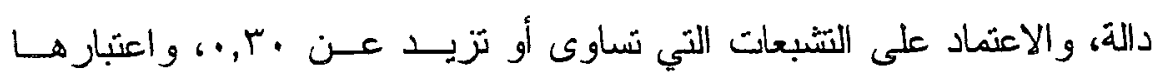

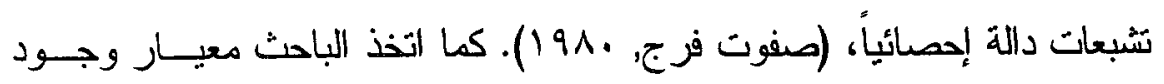

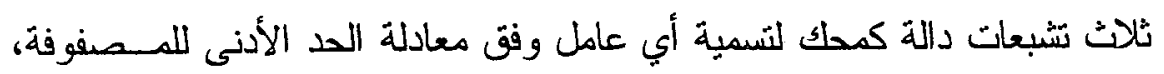

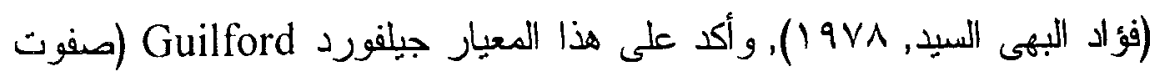

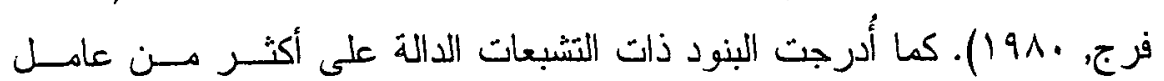

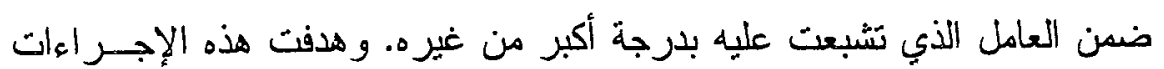
إلى تحقيق قدر أكبر من النقاء والاسنقلال العاملي لبنود المقياس.

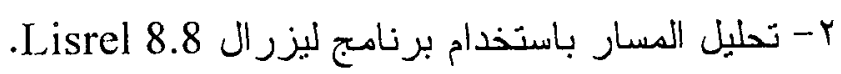
r- طريقة ألفا لكرونباخ. r- التجزئة النصفية بطريقتي سبيرمان براون وجيتمان. ع - معامل ارنباط بيرسون. 0- اختبار "ت" لدلالة الفروق بين المنوسطات غير المرتبطة. 


\section{سادسياً: حدود الدر اسة:}

تتحدد نتائج الدر اسة الحالية بالعبنة المستخدمة والتي اشتملت علــى ) (OrV) بالأدوات المستخدمة فينها، وكذللك بالأساليب الإحصائية المستخدمة في معالجة بيانات الدر اسة.

\section{:تنائجر}

قبل التحفق من البناء العاملي لمقياس الاتجاه نحو العولمة تم التأكــد من عدم وجود فزوق بين الأكور والإنات في الأداء على المقيــاس بأبعــاده

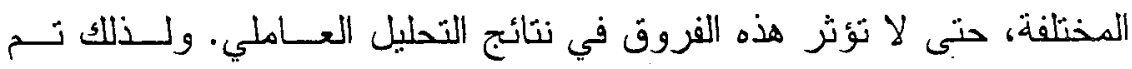
استخدم اختبار "ت" لالالة الفروق بين المتوسطات غير المرتبطة و الجــــول التالي يبين نتائج ذلك. جدول (0) نتائج اختبار "ت" لدلالة الفروق بين متوسطي درجات الذكور والإناث في الاتجاه نحو العولمة

\begin{tabular}{|c|c|c|c|c|c|c|}
\hline مستوى الدلالة & "ت" & الالمعباري & المتوسط & المنئة & المجمو عة & الأبعاد \\
\hline \multirow{2}{*}{., YqV } & \multirow{2}{*}{$1, \cdot \varepsilon$} & $0, \varepsilon$ & $Y \varepsilon, \wedge \varepsilon$ & YYO & الذكور & \multirow{2}{*}{ الآتصادي } \\
\hline & & $7, \varepsilon Y$ & $r \varepsilon, r q$ & MIY & الاناث & \\
\hline \multirow{2}{*}{$\cdot, 1 \cdot \lambda$} & \multirow{2}{*}{1,7} & $7, Y V$ & $Y \varepsilon, Y \Lambda$ & YYO & الذكور & \multirow{2}{*}{ النقافي } \\
\hline & & $0, \Sigma Y$ & $Y \Gamma, \wedge T$ & MI & الإناث & \\
\hline \multirow{2}{*}{$\cdot, 7 \wedge \varepsilon$} & \multirow{2}{*}{$\cdot, \leqslant 1$} & 0,19 & rr, ro & YYO & الذكور & \multirow{2}{*}{ السباسي } \\
\hline & & 0,09 & Yr,oO & rIY & ثالانات & \\
\hline \multirow{2}{*}{$\cdot r \cdot r$} & \multirow{2}{*}{$1, . r$} & $7, r o$ & rT,VT & TYO & الذكور & \multirow{2}{*}{ الإ علانمي } \\
\hline & & 0,01 & rE, Yq & TIY & الإناث & \\
\hline \multirow{2}{*}{$\cdot, V) V$} & \multirow{2}{*}{$\cdot, r 90$} & $11, \leqslant 9$ & $97,7 \varepsilon$ & YYO & الذكور & \multirow{2}{*}{ اللدرجة الدية } \\
\hline & & $r ., \varepsilon$. & $97, \cdot 1$ & $M T$ & الإناثث & \\
\hline
\end{tabular}


بتضح من الجدول السابق عدم وجود فروق ذات دلالة إحصائية بين منوسطي درجات الذكور والإناث في الاتجاه نحو العولمة بجميــع أبعادهـــا

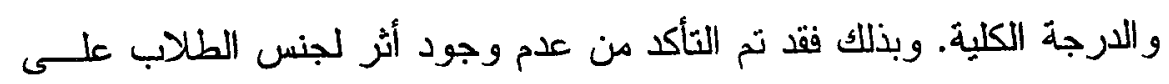
الأداء في المقياس. وبذلك يمكن إجراء التحليل العاملي للمقياس للعينة الكلية

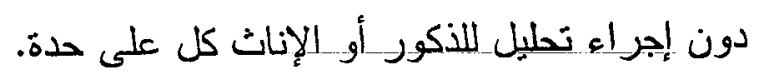

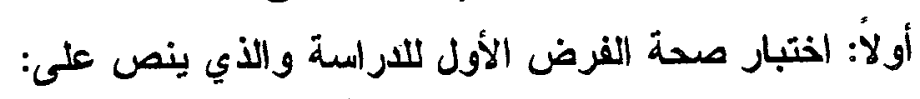

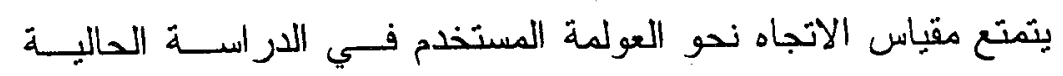

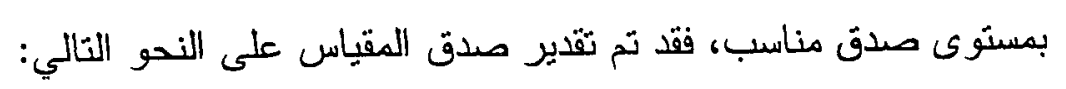

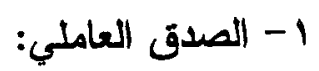

تم استخدام الصدق العاملي باستخدام طريقة المكونــات الأساسـية،

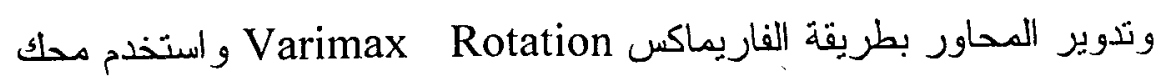

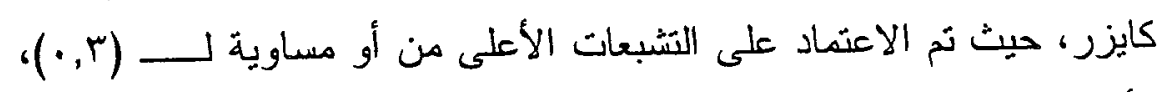

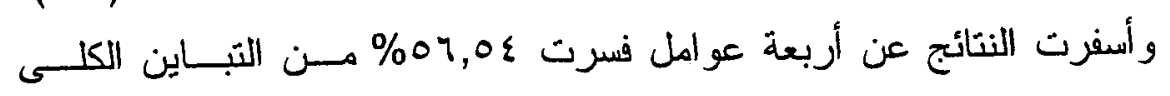

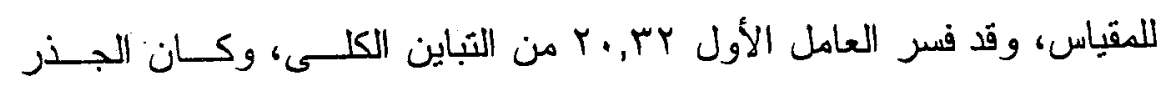

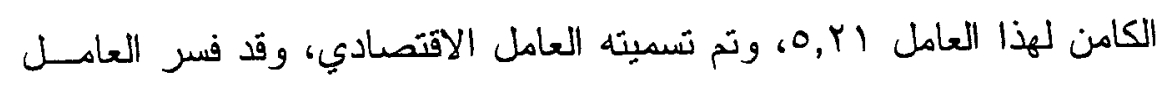

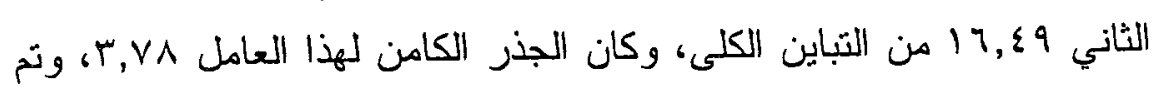

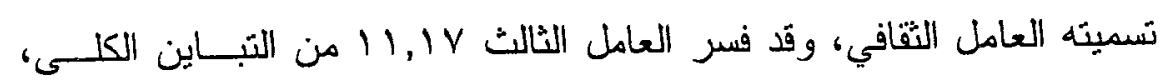

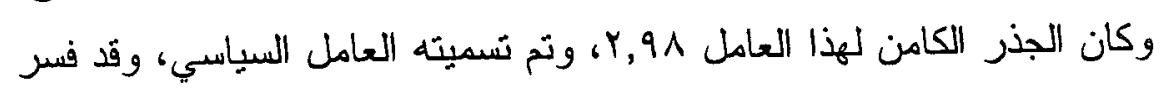

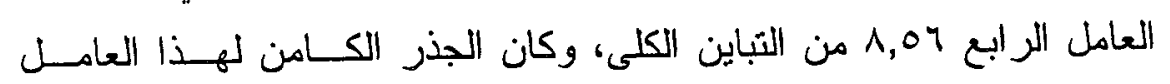

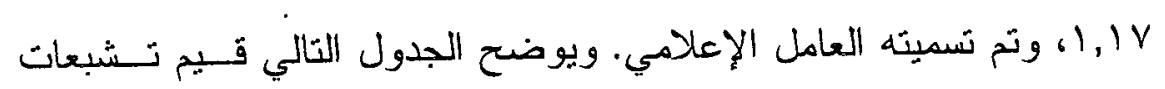

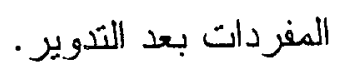



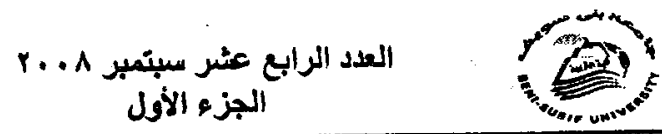

جامعة بنى سويف (مجلة كلنة التريبة)

جدول (T)

تشبعات المفزدات على عو امل مقياس الاتجاه نحو العولمة بعد التدويز

\begin{tabular}{|c|c|c|c|c|}
\hline الإعلامي & السياسي & التقامل & الاقتصادي & العبارات \\
\hline., $0 \leqslant Y$ & $\cdot, \varepsilon \leqslant \uparrow$ & $\cdot, 9 T Y$ & $\cdot, 7 T Y$ & 1 \\
\hline$\cdot, \varepsilon Y r$ &., 005 &., $0 \ldots$ & $\cdot, \varepsilon \leqslant\}$ & $r$ \\
\hline$\cdot, \wedge \varepsilon Y$ &., $0 \mathrm{~V}$ & $\therefore, O Y Y$ &.,$\xi 9 Y$ & $r$ \\
\hline., $00 r$ &., $7 Y V$ & $\cdot, 77 Y$ & $\cdot, \varepsilon \wedge \varepsilon$ & $\varepsilon$ \\
\hline$\cdot, V Y T$ & $\cdot, 7 \cdot 1$ & $0,0 . Y$ & $\cdot, 0 \wedge \mathrm{V}$ & 0 \\
\hline., 771 &., $8 \cdot 7$ &., $0 \leqslant 0$ & $\cdot, 7 \wedge$. & 7 \\
\hline., 0.0 & $\cdot, \sum \Gamma \wedge$ & $\because, \leqslant \leqslant 0$ &., $0 \leqslant Y$ & $V$ \\
\hline$\cdot, \varepsilon \backslash \Gamma$ &., 04 & $\cdot, 7.1$ & $\cdot, 7 \cdot 1$ & $\wedge$ \\
\hline
\end{tabular}

كما تم التحقق من كون هذه العوامل ثتشبع على عامل كامن واحسد

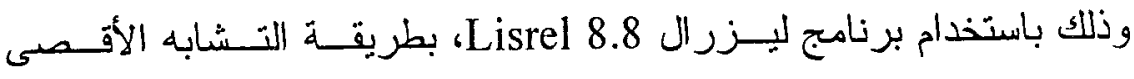
Maximum Likelihood (ML) وطالبة) كما أن توزيع درجات الأبعاد كان اعتداليأ فقد نراوحت قيم معاملات

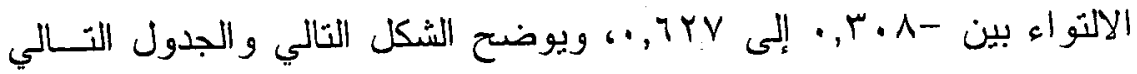

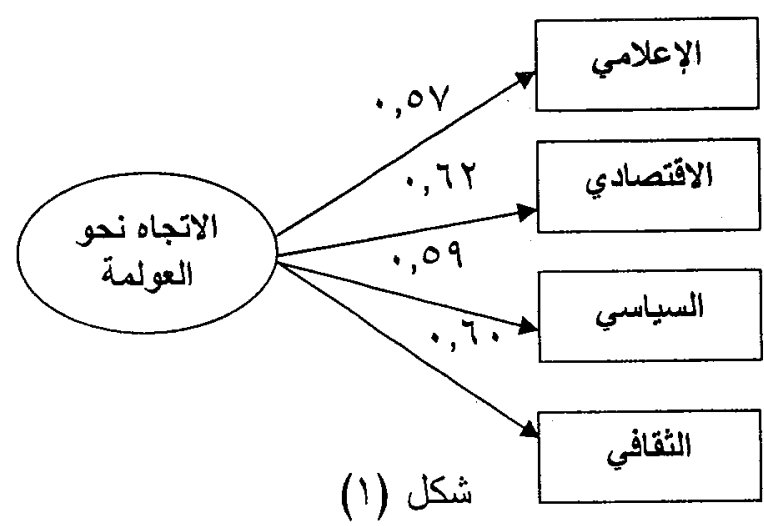

المسار التخطيطي لنموذج العامل الكامن الواحد لمقباس الاتجاه ندو العولمة. 
وقد كانت جميع التشبعات في الشكل السابق ذات دلالة إحصائية عند

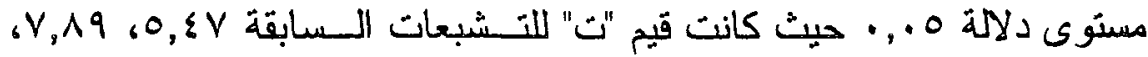

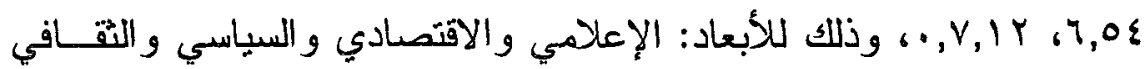

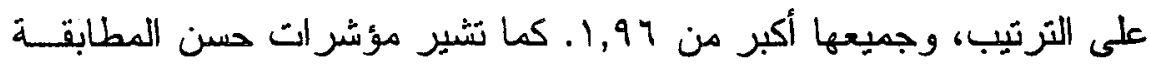

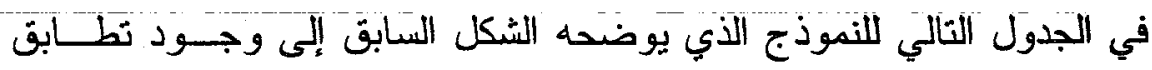

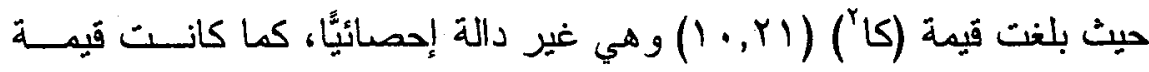

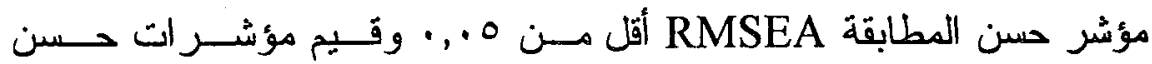

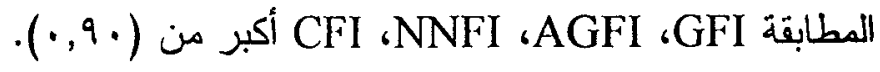
جدول (V) مؤشرات حسن المطابقة لنموذج العوامل الكامنة لمقياس الاتجاه نحو العولمة

\begin{tabular}{|c|c|c|}
\hline المدى المثالي & قيمته & الموشر \\
\hline أن تكون غير دالة & 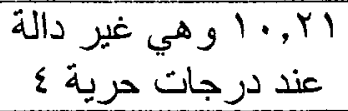 & $x^{2}$ \\
\hline هن ا إلى 0 & $1,1 \mathrm{~V}$ & $X^{2} / d f$ \\
\hline أكبر من •9, . & $\cdot, 9 \mathrm{~V}$ & GFI \\
\hline أكبر من • 9, . &., 90 & AGFI \\
\hline . . • فأقل & $\cdot, \cdot 1 \varepsilon$ & RMSEA \\
\hline أكبر من .9, . &., 91 & NNFI \\
\hline أكبر من • 9, . & $\cdot, 91$ & $\mathrm{CFI}$ \\
\hline
\end{tabular}

Y - ب - بدق المحك:

بلغت قيمة معامل الارنباط بين مقياس رتب الهوية إعداد محمد السيد عبد الرحمن (1991 (9 ) وبين درجات الطلاب على مقياس الاتجاه نحو العولمة

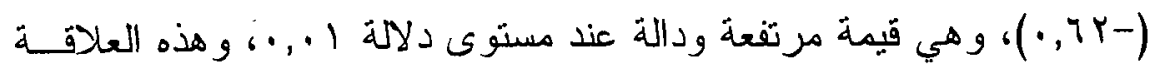

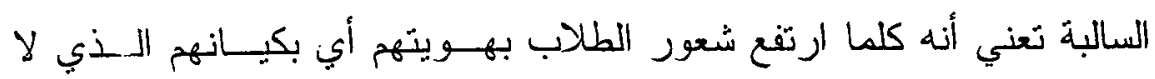
ينفصل عنهم، انخفض اتجاههم نحو العولمة التي تذعوا إلى إذابة الفو اصـل لـل 
و الحدود بين المجتمعات في جميع المجالات؛ الاجتماعبية والثقافية والسياسية والاقتصادية و الإعلامية. ثانياً: اختبار صحة الفرض الثاني للاراسة والذي ولإنصة ينص على: يتمتع مقياس الآتجاه نحو العولمة المستخدم في الدراسة الحالية بدرجة

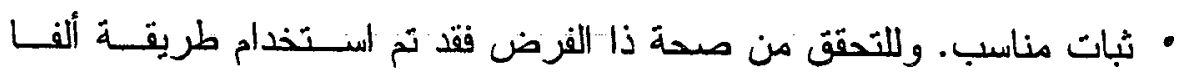

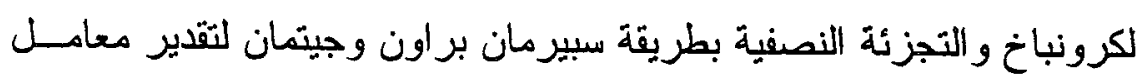
ثبات أبعاد المقياس، ويوضح الجدول التالي نتائج ذلك. جدول (^) معاملات ثبات أبعاد مقياس الاتجاه

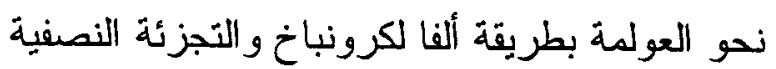

\begin{tabular}{|c|c|c|c|}
\hline \multicolumn{2}{|c|}{ التجزئة النصفية } & \multirow{2}{*}{ معامل ألفا } & \multirow{2}{*}{ الأبعاد } \\
\hline جيتمان & سبيرمان & & \\
\hline$\cdot, \wedge T$ & $\cdot, \wedge 0$ & $\cdot, \wedge 1$ & البعد الاقتصادي \\
\hline$\cdot, \wedge r$ & $\cdot, A T$ & $\cdot, \wedge Y$ & البعد الثقافي \\
\hline$\cdot, 11$ & $\cdot, \wedge 1$ & $\cdot, \times 9$ & البعد السياسي \\
\hline$\cdot, \wedge$ & $\cdot, \wedge T$ & $\cdot, \wedge V$ & البعد الإعلامي \\
\hline
\end{tabular}

كما تم تقدير معامل الارتباط بين درجة كل مفردة و الدرجة الكليسة للبعد الذي تنتمي إليه، وقد كانت جمبعها قيم مرتفعة ودالة عند مستوى دلالة

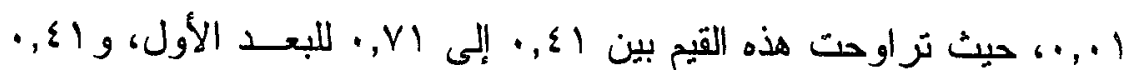

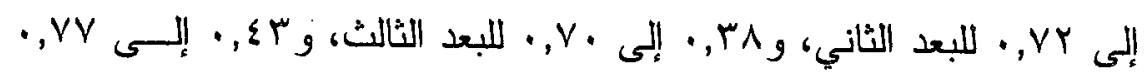

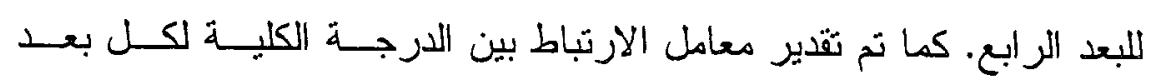

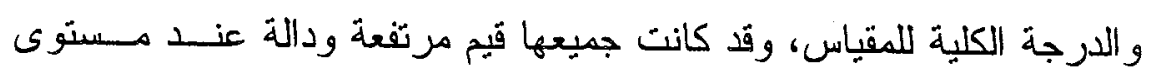
دلالة ا .,. •، ويوضح ذلك الجدولين التاليين. 
جدول (9) معامل الارتباط بين درجة كل مفردة والدرجة الكلبة للبعد الذي تنتمي إليه

\begin{tabular}{|c|c|c|c|c|}
\hline 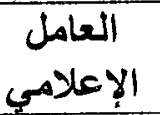 & السياسي العاهي & التُقافي & الاقتصادي & العبار ات \\
\hline., 09 &., $7 r$ & $\cdot, \leqslant\rceil$ &., 77 & 1 \\
\hline$\cdot, \varepsilon r$ & $\because, v$ & $\because, 0 Y$ & $0, \leqslant 9$ & $r$ \\
\hline., $7 r$ &.,$T \Lambda$ &., $7 \wedge$ & $\cdot, V_{1}$ & $r$ \\
\hline,$\leqslant 0$ & $\because, \varepsilon V$ & $\because, 7$. & $\cdot,\{1$ & $\varepsilon$ \\
\hline$\cdot, \vee v$ & $\therefore \leqslant 9$ & $\cdot, 7 r$ & $\because, 00$ & 0 \\
\hline$\cdot, v V$ &., $7 r$ &., 77 &., 70 & 7 \\
\hline$\cdot, v 1$ & $\because, 09$ & $\because, V Y$ & $\therefore, 09$ & V \\
\hline., $7 Y$ & $\because 70$ & $\cdot,\{1$ &., $0 T$ & $\Lambda$ \\
\hline
\end{tabular}

جدول (• (1) معامل الارنباط بين الدرجة الكلية

لكل بعد والدرجة الكلية لمقياس الاتجاه نحو العولمة

\begin{tabular}{|c|c|}
\hline معامل الارتباط & الأبعاد الأساسية \\
\hline$\cdot, \vee \vee 9$ & البعد الاقتصادي \\
\hline$\cdot, \wedge 7$ & البعد الثقافي \\
\hline$\cdot, \wedge \varepsilon$ & البعد السياسي \\
\hline$\cdot, \wedge 7$ & البعد الإعلامي \\
\hline
\end{tabular}

يتضح من النتائج السابقة تمنع المقياس بدرجة صدق وثنات مناسبين،

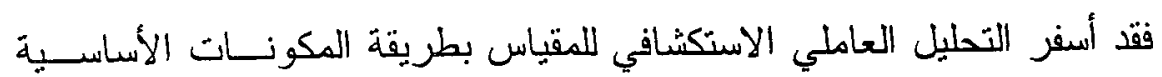

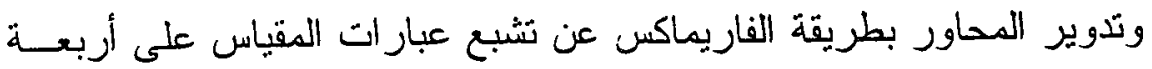

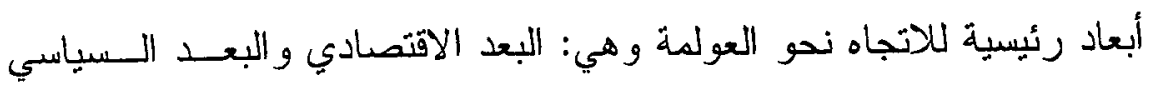

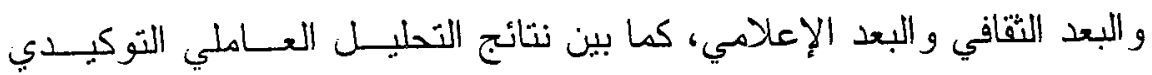

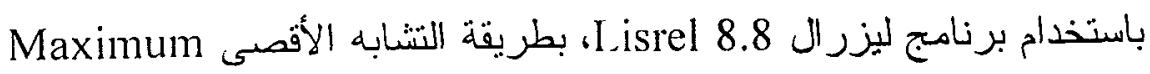

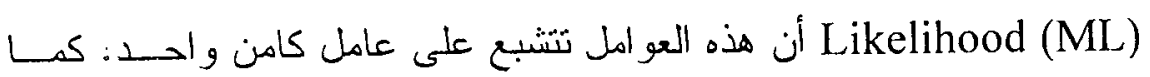


ارتبطت' درجات الطلاب على المقياس بدرجاتهم على مقياس الهوية إعـداد

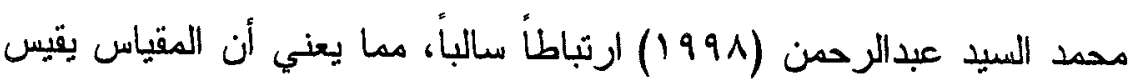
ما وضع لقياسه بالنسبة لعينة طلاب المرحلة الثانوية. كما تمنع المقيَاس بدرجات مناسبة من الثبات بطريقة ألفا لكرونبــاخ

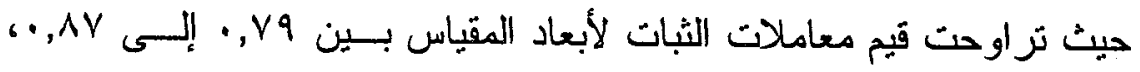

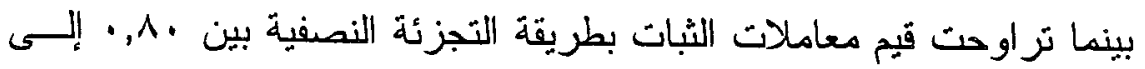

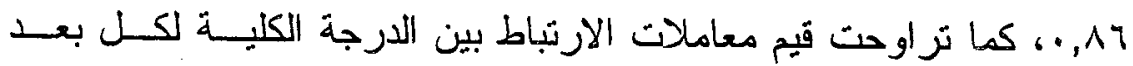

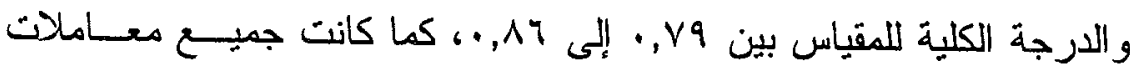

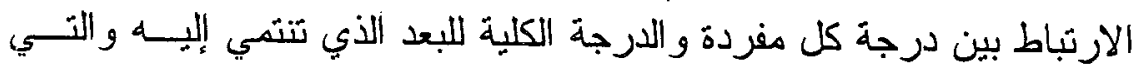

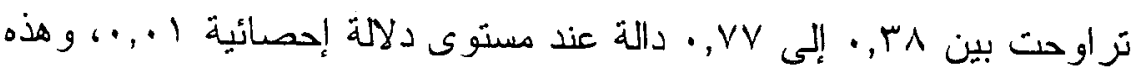
القيم تدل على مؤشرات ثبات جيدة.

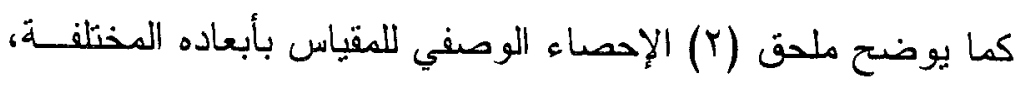
بينما يوضح ملحق (r) معايير المقياس على عينة الدراسة بالنسبة لكل بعـد

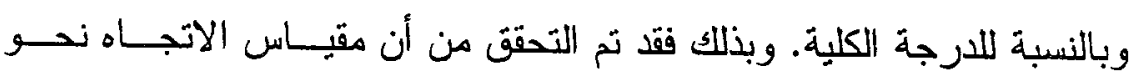
العولمة يتمتع بخصائص سيكومترية جيذة تتشابه إلى حد كبير مع خصائصها

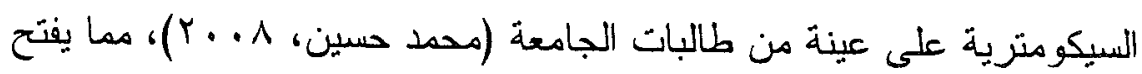
المجال أمام الباحثين لدر اسة العولمة دراسة موضو عية كميسـة مسـن جميسع

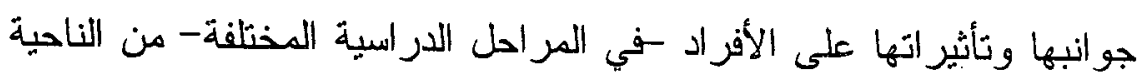

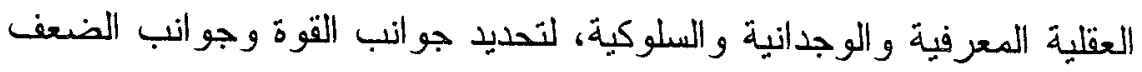

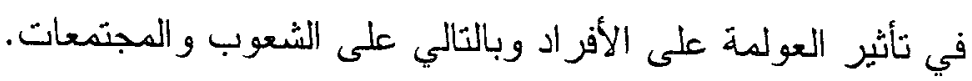




\section{التوصيات:}

في ضوء نتائج الدراسة الحالية، فإنه يمكن تقديم مجمو عة التوصبات التالية:

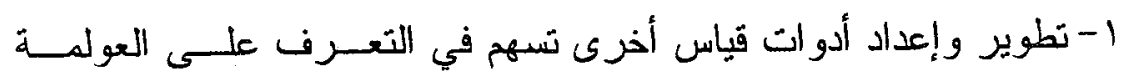
بصورة موضو عية كمية.

r- عدم اقتصار الباحثين في مجال القياس و الثقويم النفسي و التربوي على تقنين المقاييس الغربية وتعريبها، بل يجب الاهنمام ببناء أدوات لقياس الظو اهر الجديدة والمختلفة ليكون للباحثين العرب السبق في ذلك.

بxploratory factor عدم الاقتصار على التحليل العاملي الاستكشافي analysis بل يفضل التحقق مما توصل إليه هذا النوع من التحليـل، بالتحليل العاملي التوكيدي Confirmatory factor analysis.

\section{البحوث المقتنرهة:}

في ضوء نتائج الدر اسة الحالية، فإنه يمكن القيام بالعديد من البحوث و الدر اسات و التي منها:

1- التأكد من صدق وثبات مقياس الاتجاه نحو العولمة على عينـات فــي

$$
\text { مر احل در اسبة أخرى. }
$$

r- استخدام نموذج ر اش في تحليل بنود مقياس الاتجاه نحو العولمة.

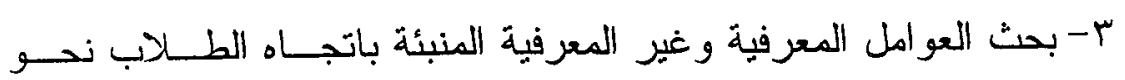

$$
\text { العولمة في مر احل در اسبة مختلفة. }
$$

؟- بحث أثز المرحلة الدر اسية في الاتجاه نحو العولمة.

0- بحث العلاقة بين الاتجاه نحو العولمة و أساليب المعاملة الو الدية. ج- بحث العلاقة بين الاتجاه نحو العولمة و الذكاء الوجداني. 

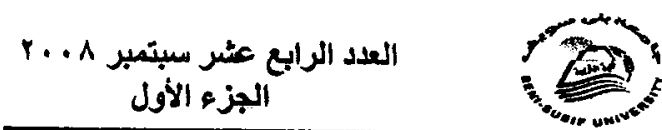

جامعة بني سويف

(مجلة كلية التربية)

\section{ralloll}

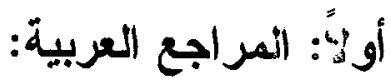

ا ـ إبر اهيم العجلوني (1999) ). العولمة و الهوية الثقافية، الواقع العربي وتحديات قرن. عمان: مؤسسة عبدالحميد شومان.

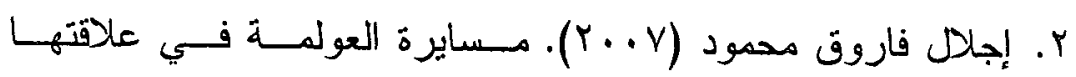
بمشكلات الطفولة. المجلة المصرية للار اسات النفسية، المجلد الـسابع

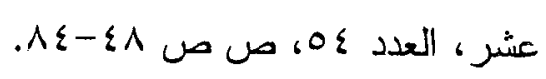

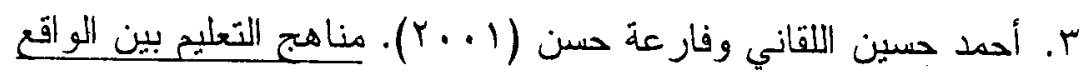

$$
\text { و المستقبل. القاهرة: عالم الكتب. }
$$

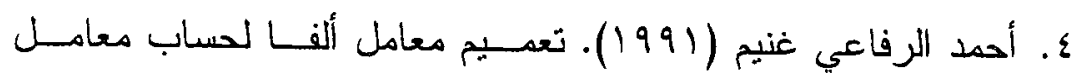

ثبات المقاييس ذات المفردات غير المتجانسة، مجلـــة كليــة الثربيـــة،

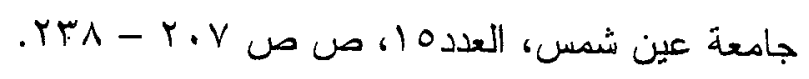

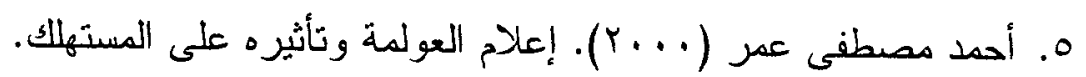

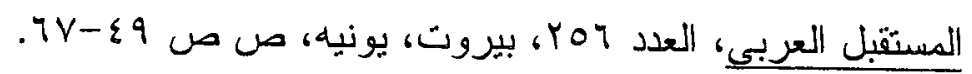

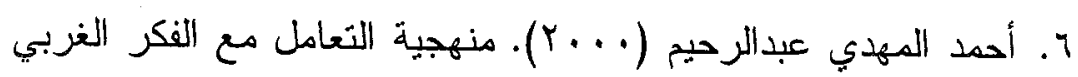

المعاصر، طبيعته ودحدداته وتقويمه ضمن المعايير المناسبة (الذاتيــة

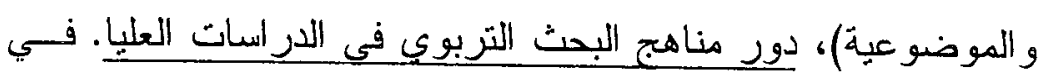

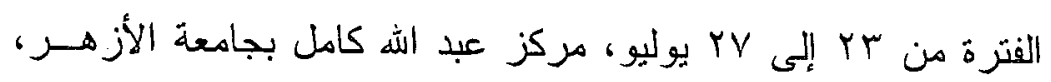

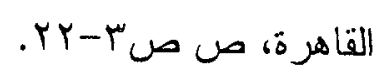

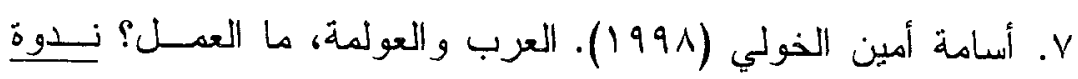

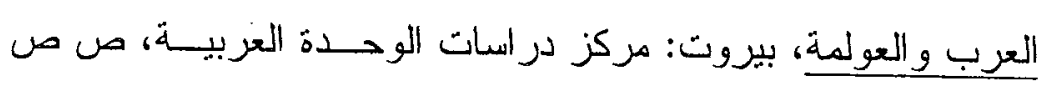

$$
. \vee 19-\varepsilon \cdot V
$$



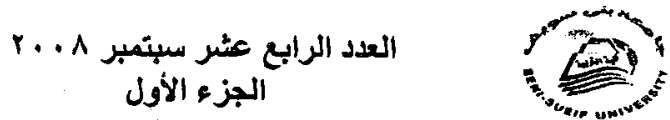

A. أمل علي المخزومي (1990). دور الاتجاهات في سـلوك الأفــر اد

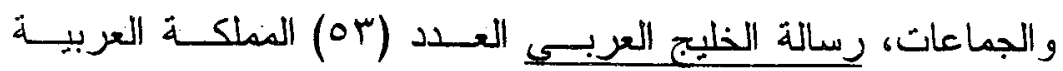

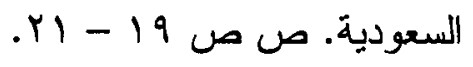

9. جاك دايلر (991 (191) التعليم ذاك الكنز الكامن، ترجمة: جـابر عبــد الحمبد جابر ، القاهرة: دار النهخة العربية.

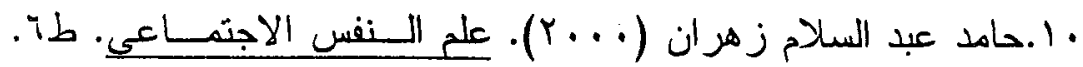
القاهرة: - مالم الكتب.

11.الحسين عضمة (9911). العالم الإسلامي وتحديات العولمة، مجلـــــ

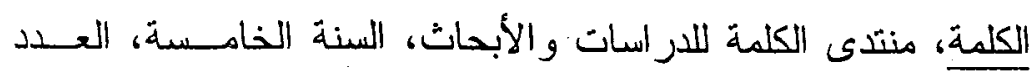

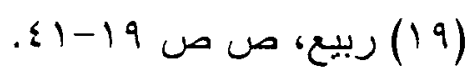

r ا.ز ايد عجير الحارثي (1991). بناء الاستفتاءات وقياس الاتجاهات. جدة: دار الفنون للنشر.

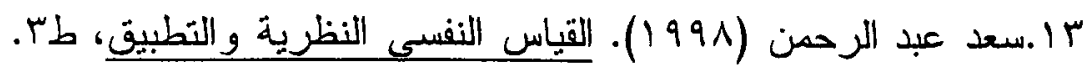

$$
\text { القاهرة: دار الفكر العربي. }
$$

؛ (.صفوت فرج (. (9 1). التحليل العاملى في العلوم السلوكية. القاهرة:

$$
\text { دار الفكر العربي. }
$$

10 ـصفوت فزج( ( . ب).القياس النفسي، ط؛، القاهرة: مكتبة الأنجلو المصرية. 17 ا.عباس عوض (1917). في علم النفي الاجنماعي. الإسكندرية: دار

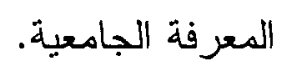

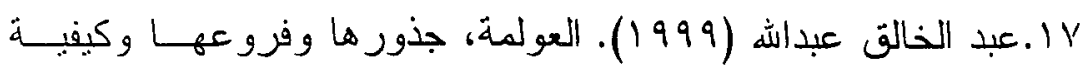

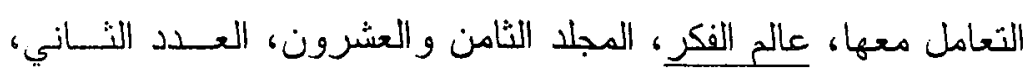

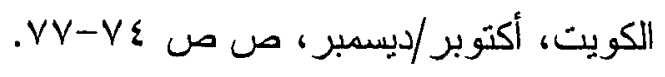


11ا:عبد العاطي أحمد الصياد (911) (191). نحو بناء مؤشر إحصائي جديد

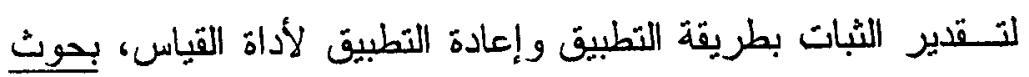

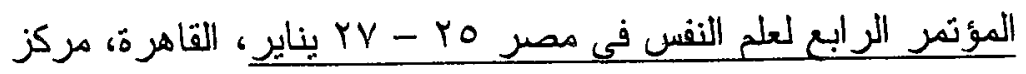

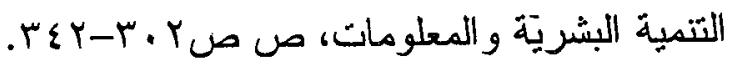

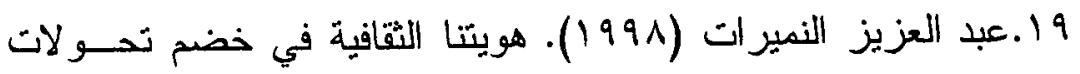

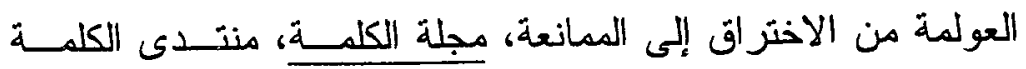

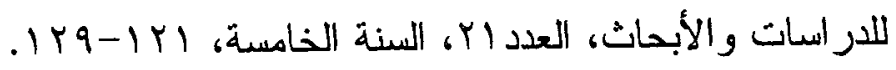

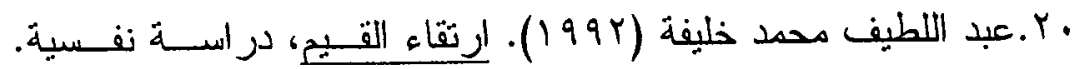
الكويت: عالم المعرفة للنشر.

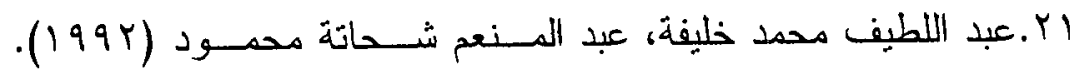
سيكولوجية الاتجاهات (المفهوم - القياس - التغير). القـاهرة: دار غريب للنشر • بون YY.عبد المنعم الحفني (ع (99)). موسوعة على النفس و التحليل النفسي، طع. القاهرة: مكتبة مدبولي. بY.فؤاد أبو حطب (999) (199). العولمة والتعليم بين عولمة التعليم وتعليم

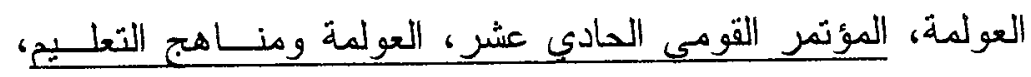

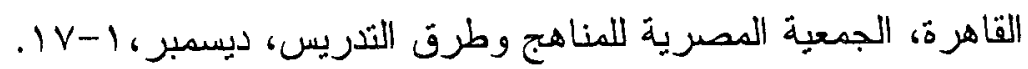

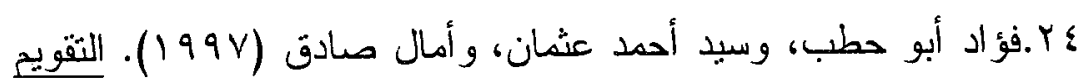
النفسي، طع. القاهرة: الأنجلو المصرية.

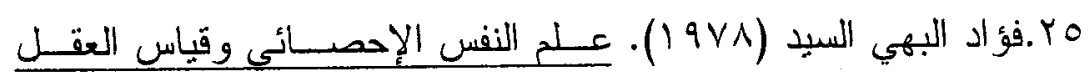
البشري. القاهرة: دار الفكر العربي.

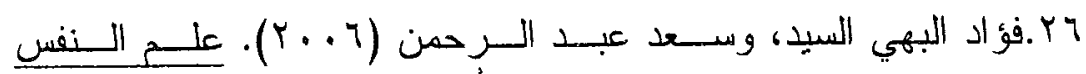
الاجنماعي رؤية معاصرة، القاهرة: دار الفكر العربي. 


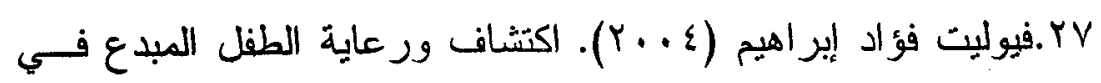

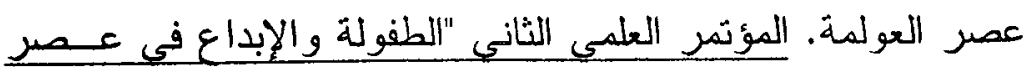

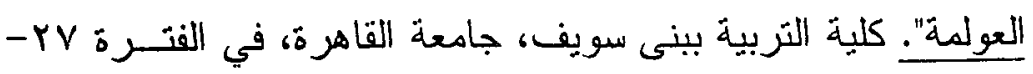

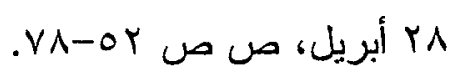

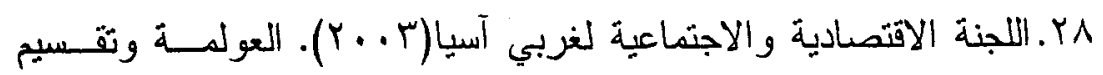
العمل بين الجنسين. سلسلة دراسات المر أة العربية(بساع). الأمم المتحدة.

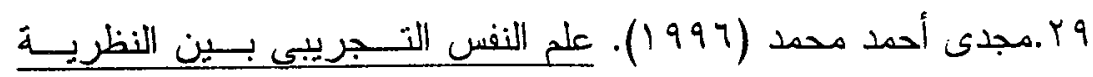
و التــطبيق. الإسكندرية: دار المعرفة الجامعية.

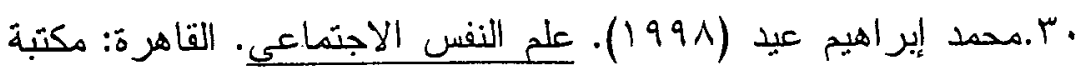
زهراء الشرق.

اس. محمد حسين سعيد (1 . . ץ). درجات امنحان الثانوية العامة "دراسة سيكومترية". رسالة ماجستير غير منشورة، كلية التربية ببني سويف، جامعة القاهرة.

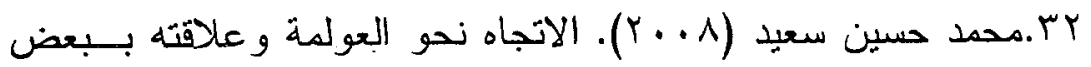
المتغيرات لدى طالبات الجامعة. المجلة المصرية للار اسات النفسية، الجمعية المصرية للدر اسات النفسية، المجلد الثامن عشر ، العدد .7، الجية

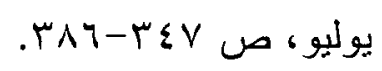

سז.محمد السيد عبد الرحمن (99191). مقياس رنب الهوية. القاهرة: دار

$$
\text { قباء للنشر . مدع }
$$

عَ.محمد شومان (1999) ). عولمة الإعلام ومستقبل النظــام العربـي.

عالم الفكر، المجلد الثامن و العشرون، العدد الثاني، الكويت، أكتــوبر

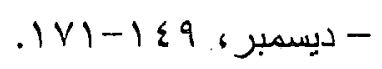


العدد الرابع عثر سبتصبر ^ ـ الجزول الجزء الأول

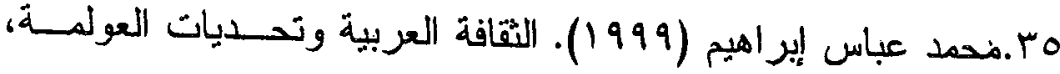

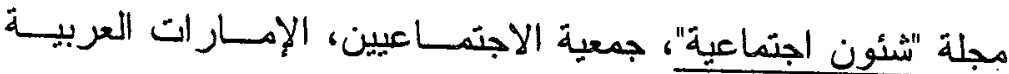

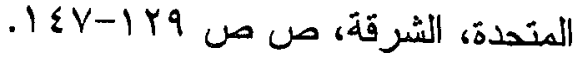

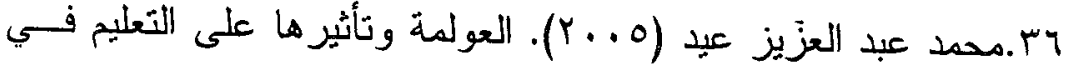

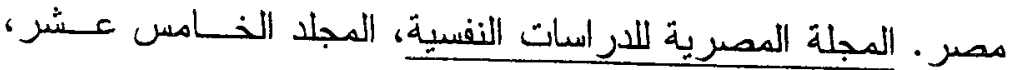

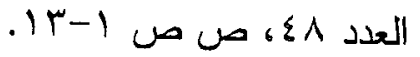

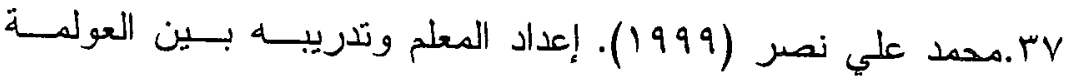
و الهوية القومية. المؤتمر القومي السنوي الحادي عـشر، "العولمـــة

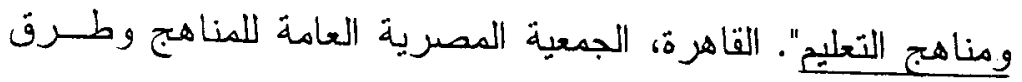

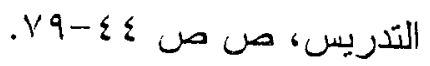

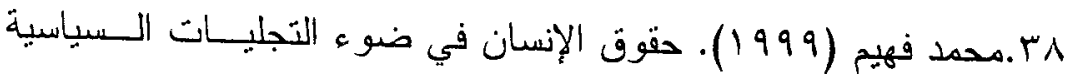

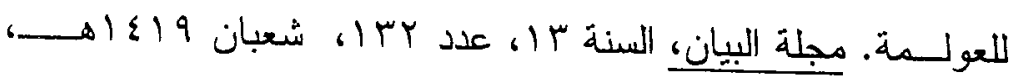

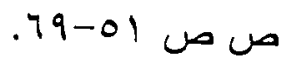

9. محمود عبد الحليم منسي (1991) ). علم النفس التربوي للمعلمهين.

$$
\text { الإسكندرية: دار المعرفة الجامعية. }
$$

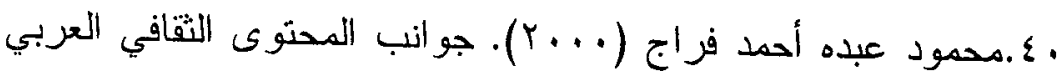
الإسلامي في كتب تعليم اللغة العربية لطلاب المعهد الأزهري لتعليم

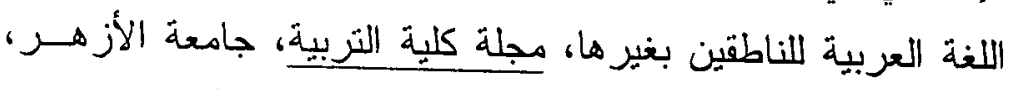

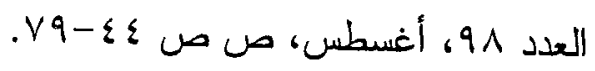

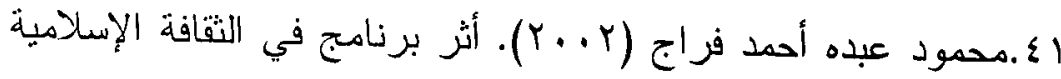

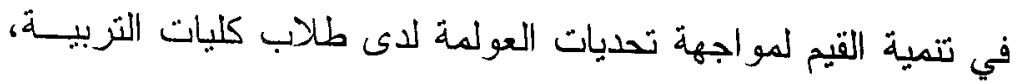

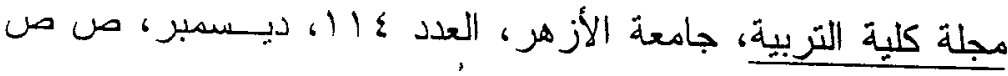



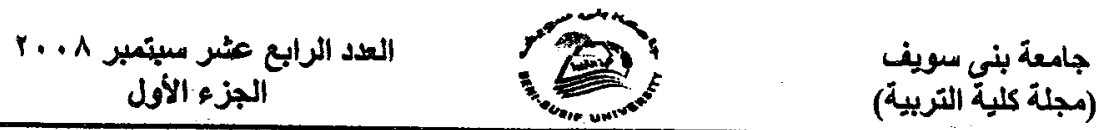

50.Bussing, R. \& Fernandez, M. \& Harwood, M. \& Hou, W. \& Garvan, C. \& Eyberg, M. \& Swanson, M. (2008). Parent and Teacher SNAP-IV Ratings of Attention Deficit Hyperactivity Disorder Symptoms: Psychometric Properties and Normative Ratings from a School District Sample. Assessment, 15 (3), 317-328.

51.Cohen, K. (1989). A psychometric study of the concept alexithymia, DAI, Vol. 50-03 B, P. 1102, Sep.

52.Cook, S. \& Heppner, P. (1997). A psychometric study of the coping measures. Journal of Educational and Psychological Measurement, 57 (6), 906-923.

53.Dag, I. (1991). Reliability and validity of the symptom checklist (Scl - $90-\mathrm{R})$ University students, Journal of Turk-Psikiyatri-Dergisi, 2 ( 1 ), 5- 12.

54.Engel, C. \& . Rutkowski, J. (2008). Globalization and the Asia Pacific: An Exploration of Efficiency and Equality Aims of Education. Critical Studies in Education, 49 (2), 143-156.

55. Finney, J. \& Piepsr, L. \& Barron, E. (2004). Examining the Psychometric Properties of the Achievement Goal Questionnaire in a General Academic Context. Educational and Psychological Measurement, 64 (2), 365-382

56. Flessner, A. \& Woods, W. \& Franklin, E. \& Keuthen, J. \& Piacentini, J. \& Cashin, E. \& Moore, S. (2007). The Milwaukee Inventory for Styles of Trichotillomania-Child Version (MIST-C): Initial Development and Psychometric Properties. Behavior Modification, 31 (6), 896-918.

57. Eox, M. \& Loope, L. (2007). Globalization and Invasive Species Issues in Hawaii: Role-Playing Some Local Perspectives. Journal of Natural Resources and Life Sciences Education, 36, 147-157. 
Y ع.معتز سيد عبد الله و عبد اللطيف محمد خليفة (1 (Y). علم الــنفس

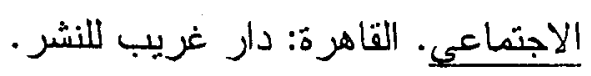

rا. هبة أحمد نصار (r . . r). الاستجابة للعولمة: الاتجاهات و التحديات

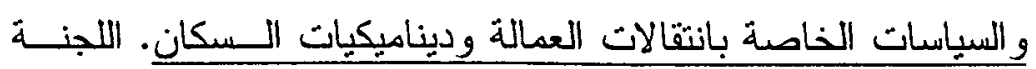

$$
\text { الاقتصادية والاجتماعية لغربي آسيا: الأمم المتحدة. }
$$

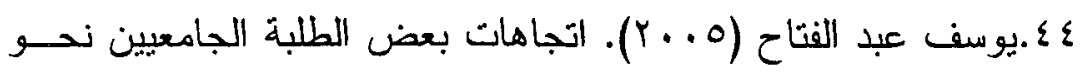

علم النفس (در اسة مقارنة بين طلاب علم النفس و غير هم بالأقـسام

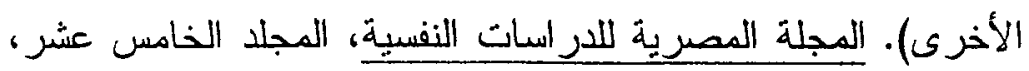

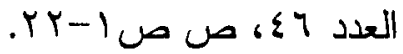

$$
\begin{aligned}
& \text { ثانيًا: المراجع الأجنبية: }
\end{aligned}
$$

45.Abdi, A. \& Ellis, L. (2007). Education and Zambia's Democratic Development: Reconstituting "Something" from the Predatory Project of Neoliberal Globalization. Alberta Journal of Educational Research, 53 (3), 287.

46.Andrews, M. (1994). Capital mobility and state autonomy. International Studies Quarterly, 38, 193-218.

47.Bikos, L. (1995). Evaluating The psychometric properties of the Missouri Occupational Card Sort, DAI, Vo. 56-11 A, P.4278.

48.Bottery, M. (2006). Education and Globalization: Redefining the Role of the Educational Professional. Educational Review, 58 (1), 95-113.

49. Brisard, E. \& Menter, I. \& Smith, I.(2007). Researching Trends in Initial Teacher Education Policy and Practice in an Era of Globalization and Devolution: A Rationale and a Methodology for an Anglo-Scottish "Home International" Study. Comparative Education,43(2),207-229. 

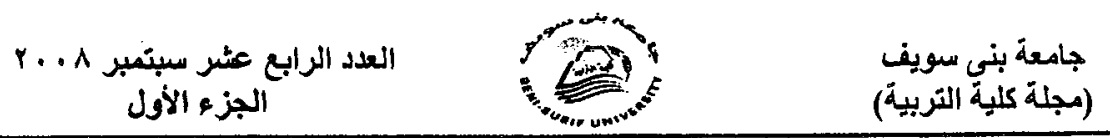

66.McDonald, R. \& Horst, H. (2007).Curriculum Alignment, Globalization, and Quality Assurance in South African Higher Education. Journal of Curriculum Studies, 39(1)19.

67.Milliron, M. (2007). Transcendence and Globalization: Our Education and Workforce Development Challenge. New Directions for Community Colleges, 20(138),31-38.

68.Milner, O. (2007). Globalization and World-Class Schools. Educational Horizons, 86 (1), 45-52.

69.Murphy, P. \& Edwards, N. \& Buehl, M. \& Zeruth, A. (2007). Using the Domain-Specific Beliefs Questionnaire with Adolescents Enrolled in High-Poverty, High-Minority Schools: Examining Psychometric Properties. Journal of Experimental Education, 76 (1), 3-25.

70.Murray, G. \& Rawlings, D. \& Allen, B. \& Trinder, J. (2003). NEO Five-Factor Inventory Scores: Psychometric Properties in a Community Sample. Measurement and Evaluation in Counseling and Development, 36(3), 140-49.

71.Ng, M. (2009). Globalization, Nationalism, and Christian Higher Education in Northeast Asia. Christian Higher Education, 8 (1), 54-67.

72.O'Leary, O. \& Gonzalez, E. \& Valdez-Gardea, C. (2006). Latinas' Practices of Emergence: Between Cultural Narratives and Globalization on the U.S.-Mexico Border. Journal of Latinos and Education, 7 (3), 206-226.

73.Papanastasiou, C, \& Angeli, C. (2008). Evaluating the Use of ICT in Education: Psychometric Properties of the Survey of Factors Affecting Teachers Teaching with Technology (SFA-T[superscript 3]). Educational Technology \& Society, 11 (1), 69-86. 
58.Goldthorpe, J. (2002). Globalization and social class. Journal of West European Politics. 1 (7), 1-21.

59. Gouveia, V. \& Milfont, L. \& da Fonseca, N. \& Coelho, M. (2009). Life Satisfaction in Brazil: Testing the Psychometric Properties of the Satisfaction with Life Scale (SWLS) in Five Brazilian Samples. Social Indicators Research, 90 (2), 267-277.

60. Hawisher, E. \& Selfe, L. \& Guo, Y. \& Liu, L. (2006).Globalization and Agency: Designing and Redesigning the Literacies of Cyberspace. College English, $68(6), 619-636$.

61.Huilan, W. (2007). Education and the Discussions on Globalization: Between "Winning the Competition" and "Social Justice". Chinese Education and Society, 40(1),2235.

62.Ibrahim, A. (2007). Linking Marxism, Globalization, and Citizenship Education: Toward a Comparative and Critical Pedagogy Post 9/11. Educational Theory, 57 (1), 89-103.

63.Kim, S. (1990). A psychometric study of parental acceptance perceived by early adolescents, DAI- B- 52/11 P. 6131.

64.Gouveia, V. \& Milfont, L. \& da Fonseca, N. \& Coelho, M. (2009). Life Satisfaction in Brazil: Testing the Psychometric Properties of the Satisfaction with Life Scale (SWLS) in Five Brazilian Samples. Social Indicators Research, 90 (2), 267-277.

65.Lowe, A. \& Lee, W. \& Witteborg, M. \& Prichard, W. \& Luhr, E. \& Cullinan, M. \& Mildren, A. \& Raad, M. \& Cornelius, A. \& Janik, M. (2008). The Test Anxiety Inventory for Children and Adolescents (TAICA): Examination of the Psychometric Properties of a New Multidimensional Measure of Test Anxiety among Elementary and Secondary School Students. Journal of Psycho-educational Assessment, 26 (3), 215-230. 
74. Paredes, M. \& Choi, M. \& Dipal, M. \& Edwards-Joseph, C. \& Ermakov, N. \& Gouveia, T. \& Jain, S. \& Koyama, C. \& Hinkle, J. \& Benshoff, M. (2008). Globalization: A Brief Primer for Counselors. International Journal for the Advancement of Counselling, 30 (3), 155-166.

75.Pons, G. \& Frias, D. \& Barrio, M. (1994). Psychometric study of the state - trait anxiety inventory for children (STAIC), Journal of Psychological. 15 (1), 45-53.

76. Raby, L. (2008). The Globalization of Journals": A Review of the 2007 "Comparative Education Review" Bibliography. Comparative Education Review, 52 (3), 461475.

77.Rohde, P. \& Seeley, R. \& Langhinrichsen-Rohling, J. \& Rohling, L. (2003). The Life Attitudes Schedule--Short Form: Psychometric Properties and Correlates of Adolescent Suicide Proneness. Suicide and LifeThreatening Behavior, 33 (3), 249-60.

78.Russell, G. (2007). Globalization, Distance Education and Hegemonic Futures. Turkish Online Journal of Distance Education, 8 (4), 8-19.

79.Scott, J. \& Short, J. \& Singer, T. \& Russ, W. \& Minnes, S. (2006). Psychometric Properties of the Dominic Interactive Assessment: A Computerized Self-Report for Children. Assessment, 13 (1), 16-26.

80.Shek, L. \& Tsang, M. \& Lam, L. \& Tang, L. \& Cheung, P. (2005). Psychometric Properties of the Chinese Version of the Psycho-Educational Profile-Revised (CPEP-R). Journal of Autism and Developmental Disorders, 35 (1), 37-44.

81.Siu, H. \& Shek, L. (2005). Psychometric Properties of the Chinese Family Assessment Instrument in Chinese Adolescents in Hong Kong. Adolescence (San Diego): an international quarterly devoted to the physiological. psychological, psychiatric, sociological, and educational aspects of the second decade of human life, 40 (160), 817. 
82. Stromquist, P. (2007). Internationalization as a Response to Globalization: Radical Shifts in University Environments. The International Journal of Higher Education and Educational Planning, 53 (1), 81-105.

83.Taylor, S. (1996). Investigation of the psychometric properties of a new measure of job satisfaction, DAI, Vol. 34-02, P. 896.

84.Tesser, A. \& Shaffer, D. (1990). Attitudes and attitude change. Annual review of psychology, 41, pp. 479-486.

85.Tomlison, J. (1991). Cultural imperialism, the John Hopkins. University press, Baltimore.

86.Vidali, L. \& Adams, D.(2006).The Challenges of Globalization: Changes in Education Policy and Practice in the Greek Context. Childhood Education, 82 (6), 358.

87.Wagoner, L.(2007). Globalization, the New Economy, and Part-Time Faculty. New Directions for Community Colleges, 27 (140), 21-27.

88.Walter, M. (2003). Public and Private Governance in Setting International Standards. In Miles K. \& David A. (eds.) Governance in a Global Economy: Political Authority in Transition. Princeton University Press.

89. Weber, E. (2007). Globalization, "Global" Development, and Teachers' Work: A Research Agenda. Review of Educational Research, 77 (3), 279-309.

90.Wu, X. \& Xu, G. \& Ma, R. \& Du, J. (2008). The Evolutionary Process of Secondary Innovation in the Context of Globalization: A Case Study. Industry and Higher Education, 22 (5), 289-296. 

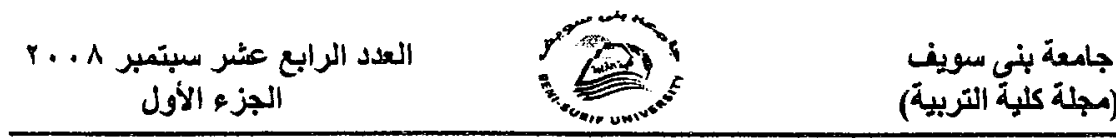

The Psychometric Properties of Attitude towards

Globalization Scale of the Secondary School Students in Beni-Suef.

By

Mohamed Hussein Said Hussein, PhD, Lecturer of Educational Psychology,

FoE, Beni suef University

\section{Abstract:}

The current study aimed to verify the Psychometric Properties of Attitude towards Globalization Scale of the secondary school students in Beni-suef, the study sample included (537) students from the first grade of secondary school and they were selected from some of the public secondary school in Beni-Suef (225 males, 312 females). There age ranged from 14 to 16 years. Attitude toward Globalization Scale prepared by the researcher (2008) were used. The results of the study indicated that the scale has suitable indicators of reliability and validity; as the exploratory factor analysis by the principals component and varimax rotated method showed four factors of the scale which are economic; political; cultural and the media factors, also the results showed negative correlations between students degrees on the scale and their degrees on the Identity Rank Scale prepared by Mohamed El S. Abdul Rahman (1998). Reliabity of the scale dimensions by Alpha method ranged from 0.79 to 0.87 , while reliability values by split half method ranged from 0.80 to 0.86 . Consequently, these values indicate acceptable reliability and validity indicators of the scale. 